\title{
Early Activation of Microglia Triggers Long-Lasting Impairment of Adult Neurogenesis in the Olfactory Bulb
}

\author{
Françoise Lazarini, ${ }^{1,2}$ Marie-Madeleine Gabellec, ${ }^{1,2}$ Nicolas Torquet, ${ }^{1,2}$ and Pierre-Marie Lledo ${ }^{1,2}$ \\ ${ }^{1}$ Institut Pasteur, Laboratory for Perception and Memory, and ${ }^{2}$ Centre National de la Recherche Scientifique Unité de Recherche Associée 2182 , F-75015 \\ Paris, France
}

Microglia, the innate immune cells of the brain, engulf and eliminate cellular debris during brain injury and disease. Recent observations have extended their roles to the healthy brain, but the functional impact of activated microglia on neural plasticity has so far been elusive. To explore this issue, we investigated the role of microglia in the function of the adult olfactory bulb network in which both sensory afferents and local microcircuits are continuously molded by the arrival of adult-born neurons. We show here that the adult olfactory bulb hosts a large population of resident microglial cells. Deafferentation of the olfactory bulb resulted in a transient activation of microglia and a concomitant reduction of adult olfactory bulb neurogenesis. One day after sensory deafferentation, microglial cells proliferate in the olfactory bulb, and their numbers peaked at day 3 , and reversed at day 7 after lesion. Similar lesions performed on immunodeficient mice demonstrate that the both innate and adaptive lymphocyte responses are dispensable for the lesion-induced microglial proliferation and activation. In contrast, when mice were treated with an antiinflammatory drug to prevent microglial activation, olfactory deafferentation did not reduce adult neurogenesis, showing that activated microglial cells per se, and not the lack of sensory experience, relates to the survival of adult-born neurons. We conclude that the status of the resident microglia in the olfactory bulb is an important factor directly regulating the survival of immature adult-born neurons.

\section{Introduction}

In mammals, neurogenesis occurs continuously in two discrete areas of the adult forebrain, the dentate gyrus of the hippocampus and the subventricular zone (SVZ) of the forebrain lateral ventricles (Ming and Song, 2011). Hippocampal adult-born neurons locally differentiate into dentate granule cells that are necessary for spatial learning, stress responses, and mood regulation, and are thought to exert specific computational functions (Clelland et al., 2009; Sahay et al., 2011; Snyder et al., 2011). SVZ adult-born neurons migrate along the rostral migratory stream (RMS) toward the olfactory bulb (OB), where they differentiate into GABA- and dopaminereleasing interneurons (Lledo et al., 2006). It is believed that this ongoing adult neurogenesis is required for maintenance of the OB circuit, for optimal olfactory functions related to innate responses, and olfactory discrimination and memory (Imayoshi et al., 2008; Valley et al., 2009; Sakamoto et al., 2011) (for review, see Lazarini and Lledo, 2011). Adult bulbar neurogenesis is also extremely sensitive to sensory experience, with numerous studies

Received Dec. 22, 2011; revised Jan. 17, 2012; accepted Jan. 21, 2012.

Author contributions: F.L. and P.-M.L. designed research; F.L., M.-M.G., and N.T. performed research; F.L., M.-M.G., N.T., and P.-M.L. analyzed data; F.L. and P.-M.L. wrote the paper.

This work was supported by the AG2R La Mondiale Group, Fondation pour la Recherche Médicale (FRM Team), Agence Nationale de la Recherche (ANR-BLAN-SVSE4-LS-110624), Labex REVIVE, and ANR-09-NEUR-004 in the frame of "ERA-NET NEURON" of FP7 program by the European Commission. We thank Matt Valley from our laboratory for helpful comments on this manuscript, Fabrice de Chaumont and Jean-Christophe Olivo-Marin (Institut Pasteur) for helping us with quantitative image analysis, Patricia Mathelier (Harvard University) for her technical assistance in behavioral experiments, and James Di Santo (Institut Pasteur) for provided access to the Rag2 $\gamma \mathrm{c}^{-1-}$ mice.

Correspondence should be addressed to Dr. Pierre-Marie Lledo, Institut Pasteur, Perception and Memory Laboratory, 25 rue du Dr. Roux, F-75724 Paris Cedex 15, France. E-mail: pmlledo@pasteur.fr.

DOI:10.1523/JNEUROSCI.6394-11.2012

Copyright $\odot 2012$ the authors $\quad 0270-6474 / 12 / 323652-13 \$ 15.00 / 0$ showing that neuronal survival is reduced by olfactory deprivation and is enhanced by olfactory learning (Lazarini and Lledo, 2011). However, the molecular mechanisms regulating the survival of adult-born neurons remain poorly identified.

Microglia, the innate immune cells of the CNS, are potential candidates to influence the survival of adult-born $\mathrm{OB}$ interneurons (Kreutzberg, 1996). Microglia derive from myeloid precursor cells, which invade the mammalian brain during development and are highly active sentinels of the brain parenchyma (Nimmerjahn et al., 2005; Ginhoux et al., 2010). Quiescent microglia play an important role in eliminating adult-born neurons experiencing programmed cell death in the hippocampus and for synaptic pruning during brain development (Sierra et al., 2010; Paolicelli et al., 2011). Not only do microglial cells contribute to the elimination of dead neurons, but they also eliminate neuroblasts in the developing cerebellum (Marín-Teva et al., 2004).

To perform all these various tasks, microglial cells are first activated in response to pathological tissue changes. Activation causes their migration to the site of injury where they proliferate and acquire new functions including phagocytic activity, and the secretion of cytokines, chemokines, growth factors, and neurotrophins (Ransohoff and Cardona, 2010; Prinz et al., 2011). However, while activation of microglia is a requisite step during pathological conditions, it can be detrimental (Ekdahl et al., 2003; Monje et al., 2003; Jakubs et al., 2008) or beneficial (Ziv et al., 2006) during the ongoing process of adult hippocampal neurogenesis.

Recently, new insights have emerged regarding the specific contribution of local microglia to SVZ neurogenesis. It has been reported that inflammation within the SVZ reduces the production of new $\mathrm{OB}$ interneurons leading to some olfactory deficits 
(Pluchino et al., 2008; Tepavčević et al., 2011). Here, we have investigated whether $\mathrm{OB}$ microglia contribute directly to the survival of adult-born neurons. For this purpose, we used the dichlobenil olfactotoxin to induce selective lesions of sensory afferents and have found that a transient activation of microglia cells contributes to the regulation of adult $\mathrm{OB}$ neurogenesis.

\section{Materials and Methods}

\section{Ethics statement and animal facilities}

All animal procedures complied with the French legislation (Rural Code articles L 214-1 to L 214-122 and associated penal consequences), European Communities Council Directive of 24 November 1986 (86/609/EEC), and European Union guidelines. They were approved by our institutional animal welfare committee (Ministry approval number A 75-15-08 for animal care facilities; approval number 75-585 for animal experimentation). We made all efforts to minimize animal suffering and the number of mice used.

\section{Mice}

Two-month-old male immunocompetent and immunodeficient mice were used in this study. Wild-type (C57BL/6J) mice were obtained from Janvier. Mice doubly deficient in the recombination activating gene 2 and the common cytokine receptor $\gamma$-chain (here called Rag2 $\gamma \mathrm{c}^{-I-}$ mice), which lack T-cells, B-cells, and natural killer cells, were propagated on a C57BL/6 background (Colucci et al., 1999). Animals were housed in transparent plastic cages $(15 \times 30 \times 30 \mathrm{~cm})$ in groups of four to five and maintained in standard conditions (room temperature of $20-22^{\circ} \mathrm{C}$ under a $12 \mathrm{~h}$ light/dark cycle, with lights on at 8:00 A.M., ad libitum access to dry food pellets and water).

\section{Chemical ablation of olfactory epithelium}

A single dose of dichlobenil (2,6-dichlobenzonitrile; $150 \mu \mathrm{g} / \mathrm{g}$ body weight; Sigma-Aldrich) freshly dissolved in dimethyl sulfoxide (SigmaAldrich; $2 \mu \mathrm{l} / \mathrm{g}$ body weight), or vehicle only was injected by the intraperitoneal route as previously described (Vedin et al., 2004).

\section{Behavior tasks}

These experiments were performed under light illumination (100 lux) during the light period (1:00 to 6:00 P.M.) in dedicated rooms. A video camera fixed to the ceiling was connected to a computer situated outside the test room and behavior was analyzed using a videotrack system (View-point). Mice were used only once for each test.

Buried food finding test. A slight modification of the buried-food finding test described by Jamain et al. (2008) was used to assess olfaction. Four days before testing, mice were fasted for $20 \mathrm{~h}$, and then received several pieces of "Coco Pops" cereal (Kellogg's). Twenty hours before testing, mice were fasted and then individually placed into a fresh cage $(37.5 \times 17 \times 18 \mathrm{~cm})$ with standard bedding for $20 \mathrm{~min}$. While mice were placed in another similar cage for $2 \mathrm{~min}, \sim 10-12$ pieces of cereals were hidden in $1.5 \mathrm{~cm}$ bedding in a corner of the test cage. The tested mouse was then positioned in the opposite corner, and the latency to find the food (defined as the time to locate food and initiate digging) was recorded using a chronometer. The test was performed during a $15 \mathrm{~min}$ period. As soon as food was uncovered, mice were removed from the cage. Thirteen minutes later, mice underwent similar testing procedures with visible Coco Pops, placed upon the bedding.

Innate avoidance test. To further assess odorant detection, we used the innate avoidance test described by Jaskelioff et al. (2011) with minor modifications. The test cages were open boxes $(36 \times 24 \times 29 \mathrm{~cm})$ with two compartments separated by an aluminum partition (holes, $0.5 \mathrm{~cm}$ diameter). The lower compartment was $2.5 \mathrm{~cm}$ high. Mice were fasted for $20 \mathrm{~h}$, and then acclimated individually in a cage similar to the test cage for 20 min before testing. Mice were exposed to either $40 \mu \mathrm{l}$ of either water or increasing concentrations of 2-methylbutyric acid (2-MB acid dissolved in water) by placing a filter paper dish $(70 \mathrm{~mm})$ in the lower compartment. Each exposure lasted $3 \mathrm{~min}$. An interval of 2 min separated trials. For analysis, the test cage was virtually divided in three equally sized zones, including the scented zone (i.e., zone 1). Using the videotrack system, both trajectory and time spent in each zone were determined at
Table 1. Detailed information on the primary antibodies used in this study

\begin{tabular}{|c|c|c|c|}
\hline Antibody & Manufacturer and catalog \# & Marker of the following & $\begin{array}{l}\text { Working } \\
\text { dilution }\end{array}$ \\
\hline \multirow[t]{2}{*}{ Anti-BrdU } & Abcys; ABC 117-7513 & Proliferating cells & $1: 1000$ \\
\hline & Megabase Research Products & & $1: 2000$ \\
\hline Anti-CD45 & $\begin{array}{l}\text { Millipore Bioscience Research Reagents; } \\
\text { CBL } 1326\end{array}$ & $\begin{array}{l}\text { Leukocytes, activated } \\
\text { microglia }\end{array}$ & $5 \mu \mathrm{g} / \mathrm{ml}$ \\
\hline Anti-CD68 & Serotec; MCA1957GA & Activated microglia & $0.5 \mu \mathrm{g} / \mathrm{ml}$ \\
\hline Anti-DCX & Abcam; ab18723 & Neuroblasts & $0.5 \mu \mathrm{g} / \mathrm{ml}$ \\
\hline Anti-GAP43 & Sigma-Aldrich; G9264 & Axon of young & $1: 100$ \\
\hline Anti-GFAP & Dako; 20334 & Astrocytes & $4 \mu \mathrm{g} / \mathrm{ml}$ \\
\hline Anti-lba1 & Wako Chemicals; 016-20001 & Microglia & $1 \mu \mathrm{g} / \mathrm{ml}$ \\
\hline Anti-NeuN & $\begin{array}{l}\text { Millipore Bioscience Research Reagents; } \\
\text { MAB377 }\end{array}$ & Neurons & $5 \mu \mathrm{g} / \mathrm{ml}$ \\
\hline Anti-0MP & Wako; 544-10001 & urons & $1: 2000$ \\
\hline Anti-TH & ImmunoStar; 22941 & Dopaminergic neurons & $1: 4000$ \\
\hline
\end{tabular}

day 11 and day 28 after lesion. Animals were considered to have an innate avoidance behavior when they kept away from the scented zone.

Dark/light test. This test was used to assess anxiety-related behavior. The emotional response to anxious stimuli, such as highly illuminated situation, was evaluated using an apparatus consisting in two compartments of equal size $(21.5 \times 15.5 \times 25 \mathrm{~cm})$ : A white brightly illuminated compartment (500 lux) connected to a black very dark one (3 lux) through a small door. Mice were placed individually into the white compartment. The latency to enter the dark side, the time spent in each compartment, and the number of transitions between compartments were determined over a 5 min period using the videotrack system at day 30 after lesion. Animals were considered "anxious" when they avoided staying in the highly illuminated box.

\section{5-Bromo-2' -deoxyuridine administration}

To label fast-proliferating cells, mice were injected intraperitonally with a DNA synthesis marker, 5-bromo-2'-deoxyuridine (BrdU) (SigmaAldrich), at $100 \mathrm{mg} / \mathrm{kg}$ (freshly prepared in sterilized $0.9 \% \mathrm{NaCl}$ ), $2 \mathrm{~h}$ before perfusion. To label all proliferating cells, BrdU $(1 \mathrm{mg} / \mathrm{ml})$ was given in drinking water for 1 week.

\section{Antiinflammatory treatment}

Minocycline (Sigma-Aldrich) freshly dissolved in sterilized $0.9 \% \mathrm{NaCl}$, or vehicle was injected intraperitoneally during 3 or $35 \mathrm{~d}$ after the lesion. Mice were treated with minocycline $(50 \mathrm{mg} / \mathrm{kg})$ twice daily for the first $2 \mathrm{~d}$ ( $8 \mathrm{~h}$ interval) and once daily for the next $5 \mathrm{~d}$, followed by $25 \mathrm{mg} / \mathrm{kg}$ once daily as described previously (Ekdahl et al., 2003).

\section{Immunohistochemistry}

Primary antibodies used in this study and their working dilutions are listed in the Table 1.

Immunoperoxidase staining. For single immunolabeling of either tyrosine hydroxylase (TH), doublecortin (DCX), and cluster of differentiation 68 (CD68), brain sections were first incubated for $20 \mathrm{~min}$ in citrate buffer $(0.1 \mathrm{M})$ with $\mathrm{pH} 9.0$ at $80^{\circ} \mathrm{C}$, and then incubated with the appropriate primary antibody. Labeled cells were detected using a corresponding biotinylated secondary antibody (Jackson ImmunoResearch Laboratories) and developed using the $\mathrm{ABC}$ system (Vector Laboratories) and 3,3'-diaminobenzidine (0.05\%; Sigma-Aldrich) as previously described (Lazarini et al., 2009).

Immunofluorescence staining. Single-cell analysis of coexpression of different markers was performed using double (or triple)-labeling immunohistochemistry as previously described (Alonso et al., 2008). For glial fibrillary protein (GFAP), CD68, and CD45 immunostaining, antigen retrieval was performed for $20 \mathrm{~min}$ at $80^{\circ} \mathrm{C}$ in $1 \mathrm{~mm}$ EDTA. For BrdU staining, DNA was denatured with $2 \mathrm{~N} \mathrm{HCl}$ for $30 \mathrm{~min}$ at $37^{\circ} \mathrm{C}$. Incubation with primary antibodies was performed individually [except for anti-olfactory marker protein (OMP) and anti-growth association protein 43 (GAP43), which were incubated together overnight] and followed by an incubation with corresponding Alexa-conjugated secondary antibodies (Jackson ImmunoResearch 
Laboratories). Sections were stained with the nuclear dye DAPI $\left(4^{\prime}, 6^{\prime}-\right.$ diamidino-2-phenylindole) before mounting.

Image acquisition, quantification, and densitometry analysis. Immunoperoxidase staining was quantified by measuring optical density using custom-written QUIA software (http://www.bioimageanalysis.org) as previously described (Lazarini et al., 2009). For each animal, eight sections $400 \mu \mathrm{m}$ apart were selected, using the accessory OB as landmark. Double and triple immunofluorescence staining was analyzed in three dimensions using either a confocal laser-scanning microscope (LSM 510; Zeiss) or an Apotome microscope (Aviovert 200M; Zeiss). Colocalization was evaluated in single optical planes taken through the entire $z$-axis of each cell. All BrdU ${ }^{+}$cells present in the glomerular layer (GL) were scanned and analyzed (three to six slices per animal; three animals analyzed per group). For double-staining analysis with ionized calcium binding adaptor molecule (IBA1) and CD45, or BrdU and CD68, positive cells were counted in 20 adjacent glomeruli (six slices per animal; three to four animals analyzed per group). Cells immunoreactive for DCX were counted in the entire GL and the dorsomedial part of the GCL (8-10 slices per animal, 3-4 mice analyzed per group). Data are expressed as number of simple-labeled cells, double-labeled cells, or the percentage of double-labeled cells present in the GL or GCL.

\section{Protein quantification by dot-blot immunoassay}

The OB levels of OMP and GAP43 was quantified by dot-blotting techniques as previously described (Tham et al., 2001). The density of the signals was quantified by a Epson Expression 1680 Pro scanner using NIH Image software.

\section{Statistical analyses}

All data are expressed as mean \pm SEM. Statistical analyses were performed using Prism software (GraphPad; version 5.0c), with $p<0.05$ considered significant. Data were analyzed using unpaired two-tailed Student's $t$ test, one-way ANOVA, or two-way ANOVA followed by Bonferroni's post hoc test, when appropriate. In the buried food-finding test, log-rank (Mantel-Cox) test was used to evaluate differences between experimental groups.

\section{Results}

\section{Effectiveness of the olfactory lesion}

Olfactory sensory neurons (OSNs) of the olfactory neuroepithelium $(\mathrm{OE})$ project via the olfactory nerve to glomeruli in the $\mathrm{OB}$ where they synapse on the dendrites of output mitral/tufted cells. Dichlobenil administration results in OB deafferention due to a rapid degeneration of OSNs and their axonal projections (Alonso et al., 2008). We evaluated the impact of this lesion by quantifying staining for OMP (a cell marker specific to mature OSNs) and for GAP43 (a cell marker specific to immature OSNs) in the GL. While a strong immunoreactivity for OMP and GAP43 characterizes the axon processes within the GL in the control OB (Fig. $1 A, B)$, both markers were drastically reduced following administration of dichlobenil (treatment effect for OMP: $F_{(1,17)}=$ 65.53, $p<0.0001$; treatment effect for GAP43: $F_{(1,20)}=10.56$, $p=0.0040)$. Immunolabeling for OMP and GAP43 began to decline $7 \mathrm{~d}$ after dichlobenil treatment and reaches the lowest expression level at $14 \mathrm{~d}$, reflecting the degeneration rate of OSN terminals (Fig. 1 $A, B$ ). Both expression levels remained suppressed even 1 month later consistent with a previous report (John and Key, 2003). Nevertheless, we noted a slight increase in both OMP and GAP43 levels at $28 \mathrm{~d}$ (Fig. $1 \mathrm{~B}$ ), which might reflect the first attempts of OSNs to reinnervate the GL. This hypothesis is supported by previous studies showing that, between 8 and 18 weeks after dichlobenil administration, OSNs start partially regenerating some areas of the $\mathrm{OE}$ and innervate inappropriate glomeruli (John and Key, 2003; Vedin et al., 2004).

Since dichlobenil treatment is efficient in lesioning olfactory sensory afferents, we investigated whether the $\mathrm{OB}$ neural activity is impaired by quantifying $\mathrm{TH}$ immunostaining at 21 and $28 \mathrm{~d}$ after lesion (Fig. $1 C$ ). $\mathrm{TH}$, the rate-limiting enzyme in the catecholamine synthesis, is expressed only in dopaminergic periglomerular (PG) neurons through an activity-dependent manner (Baker et al., 1983; Kiyokage et al., 2010; Kosaka and Kosaka, 2011). We found a drastic decrease in the TH immunoreactivity in lesioned mice compared with controls (Fig. 1C) at 21 and $28 \mathrm{~d}$ after lesion $\left(F_{(2,17)}=12.95 ; p<0.0001\right)$. This finding indicates that olfactory deafferentation lasts at least 1 month and supports previous observations made from distinct methods to induce olfactory deafferentation (Baker et al., 1983; Mandairon et al., 2006; Bastien-Dionne et al., 2010; Parrish-Aungst et al., 2011).

Finally, we confirmed the effectiveness of sensory deafferentation by assessing the olfactory behavior of dichlobenil-treated mice. No change in locomotor activity was observed after OE lesioning using an open-field paradigm (data not shown). Then, we assessed the latency to uncover small pieces of cereals hidden beneath a layer of cage bedding (Fig. 1D). While control mice find cereals within $45 \mathrm{~s}$, treated mice exhibit much higher latency (fivefold increase at $25 \mathrm{~d}$ after lesion: Kaplan-Meier survival analysis, Mantel-Cox log-rank test, $\chi_{(1)}^{2}=14.22, p=0.0002$; Fig. $1 D$ ) without change when food was made visible (Fig. $1 D$ ). This observation made using attractive food odorants indicates a deficit in olfaction following the loss of OSN. Similarly, innate avoidance tests were performed using increasing concentrations of $2-\mathrm{MB}$ acid, an odorant emitted by spoiled foods that triggers innate aversive responses (Kobayakawa et al., 2007; Jaskelioff et al., 2011). As a control, water was first presented to each individual mouse. We found that this olfactory behavior was strongly impaired by OE lesioning for at least 1 month (treatment effect for day 11: $F_{(1,40)}=6.23, p=0.0168$; treatment effect for day 28: $\left.F_{(1,24)}=11.51, p=0.0024\right)$. Control mice showed avoidance response to the $2-\mathrm{MB}$ acid presented at $10^{-4}$ and $10^{-5} \mathrm{M}$, spending more time in the cage zones faraway from the odorant source (Fig. $1 E$ ). In contrast, lesioned mice showed noninterest, or even attraction, to 2-MB acid at all concentrations used, thus staying longer in the scented zone (Fig. 1E,F). Collectively, these results are consistent with previous studies reporting altered sense of smell after dichlobenil treatment (Genter et al., 1996; Vedin et al., 2004). Because anosmia may induce behavioral alterations such as anxiety, which might not be detected by open-field paradigm, dark/light tests were performed (Fig. 1G). We found that the total time spent in the light compartment of the box did not differ significantly among the control and the lesioned group (data not shown). Meanwhile, lesioned mice spent less time in the light compartment before leaving it for the first time (30 d after lesion, $t_{(29)}=3.894, p=0.0005$ ). These findings indicate that lesioned mice are more anxious than controls in a novel anxiogenic environment. Thus, dichlobenil treatment produced a dramatic $\mathrm{OB}$ deafferentation persisting for at least 1 month and, during this period, produced robust impairment in olfactory-guided behavior.

\section{The survival of new neurons decreases after sensory deafferentation}

We evaluated the effects of sensory deafferentation on adult neurogenesis by quantifying the number of adult-born neurons located in the $\mathrm{OB}$ during the first month after lesion. We first analyzed DCX immunoreactivity in the different OB layers including the GL, the granule cell layer (GCL) and the RMS located at the core of the OB (RMSob). DCX is a neuronal marker transiently expressed by newly generated PG and GC cells (Brown et al., 2003). We observed a decreased number of DCX + cells in the GL of lesioned mice (treatment effect: $F_{(1,21)}=8.451, p=0.0084$ ) 

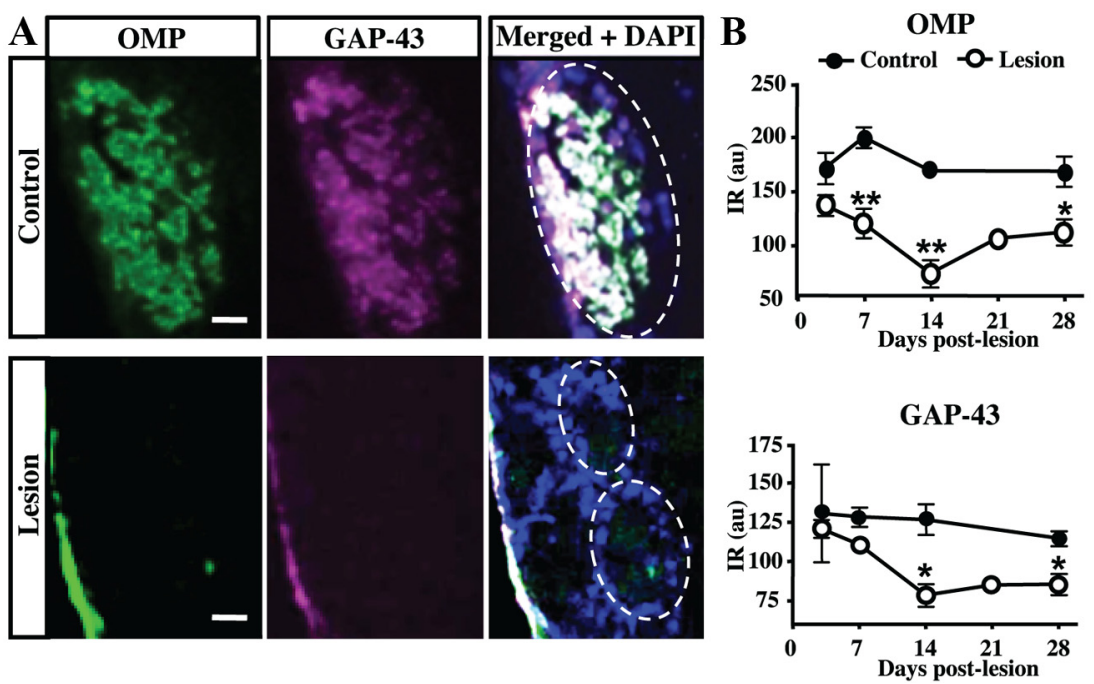

D Buried food finding -Ctrl 口Lesion d25

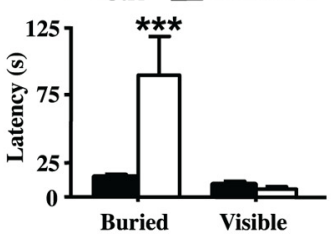

G Dark/light test

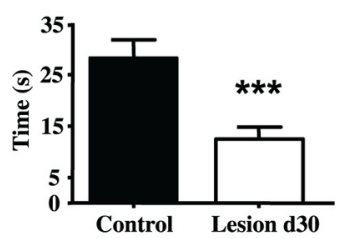

$\mathbf{E}$
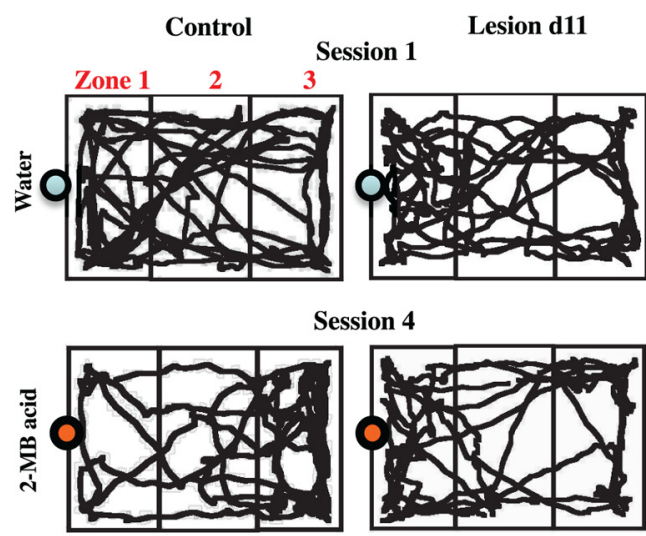

Session 4

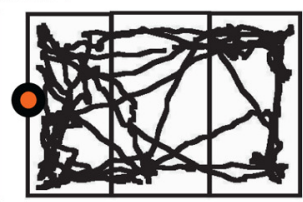

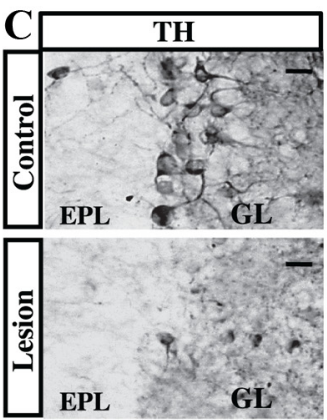

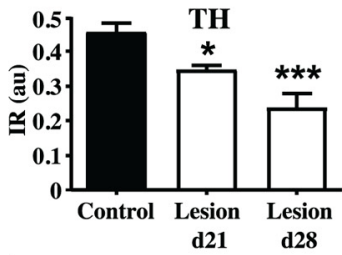

F Olfactory avoidance test
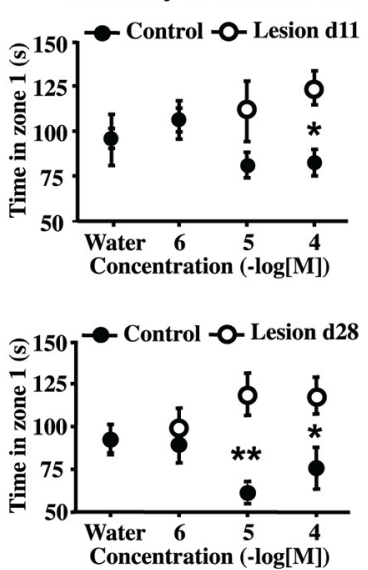

Figure 1. Sensory deafferentation reduces $0 B$ activity and impairs olfaction. $A$, The immunostaining for $0 M P$ (green) and GAP43 (purple) shows expression in the glomeruli of control (top panels) and lesioned (bottom panels) 0 E. The efficacy of OB deafferentation is exhibited by the low expression of both OMP and GAP43 after diclobenil injection. The dotted lines delineate glomeruli. $B$, Time course analysis of OMP and GAP43 expression (optical density) in the $0 B$ of control and lesioned mice $(n=3-4)$. C, Photomicrographs of coronal sections showing TH immunoreactivity in the control (top) or deafferented (middle) $0 B, 1$ month after lesion. Note the strong decrease in the TH immunoreactivity at 21 and $28 \mathrm{~d}$ after lesion (bottom; $n=4-6$ ). $\boldsymbol{D}$, Latency to find food in the buried food-finding test performed at $25 \mathrm{~d}(n=8)$ after lesion. Lesioned mice showed a larger latency to find the hidden food than controls, and a similar latency to find the visible food than controls. $\boldsymbol{E}$, Representative tracings of control and deafferentated mouse locomotion ( $11 \mathrm{~d}$ after lesion) during a 3 min exposure either to water or to $2-\mathrm{MB}$ acid $\left(10^{-4} \mathrm{M}\right)$. The position of the mouse was assessed in the cage test by analyzing three zones (delineated by gray lines) named zone-1, -2 , and -3 . Mice were first exposed to water, and then to increasing concentrations of 2-MB acid. The bottom panels are tracings of mice for the last concentration of 2-MB acid $\left(10^{-4} \mathrm{M}\right)$. While control mice avoid 2-MB mainly in the scented zone 1, lesioned mice showed attraction, or noninterest, to 2-MB.F, Time spent in scented zone 1 with water or 2-MB acid for control and deafferentated mice at $11 \mathrm{~d}$ ( $n=8$; top graph) and $28 \mathrm{~d}(\mathrm{n}=4$; bottom graph) after lesion. All control mice showed an avoidance response to 2-MB acid presented at $10^{-4}$ and $10^{-5} \mathrm{M}$, while lesioned mice were nonresponsive at all concentrations. $G$, Latency to reach the dark compartment during 5 min in the dark/light test performed at $30 \mathrm{~d}(n=15-16)$ after lesion. Lesioned mice showed a shorter latency to enter for the first time into the dark compartment than controls. ${ }^{*} p<0.05$, compared with control $(\boldsymbol{B}, \boldsymbol{C}, \boldsymbol{F}) ;{ }^{* *} p<0.01$, compared with control $(\boldsymbol{B}, \boldsymbol{F}) ;{ }^{* * *} p<0.001$, compared with control $(\boldsymbol{C}, \boldsymbol{D}, \boldsymbol{G})$. Abbreviations: au, Arbitrary units; EPL, external plexiform layer; $\mathrm{GL}, \mathrm{glomerular} \mathrm{layer;}$ IR, immunoreactivity. Scale bars: $\boldsymbol{A}, 25 \mu \mathrm{m} ; \boldsymbol{C}, 20 \mu \mathrm{m}$. Error bars indicate SEM.

at 21 and $28 \mathrm{~d}$ after lesion (Fig. $2 A, B$ ). This decrease was accompanied by a strong reduction of DCX immunoreactivity in the GCL at 21 and $28 \mathrm{~d}$ after lesion (Fig. $2 B$; treatment effect: $F_{(1,15)}=$ $8.08, p=0.0124$; comparison between control and lesioned mice at $\left.28 \mathrm{~d}: t_{(5)}=3.805, p<0.01\right)$, due to a reduction in the number of DCX + cells in the GCL (Fig. $2 C ; t_{(6)}=5.38 ; p=0.0017$ at $28 \mathrm{~d}$ after lesion). However, we found that DCX immunoreactivity in the RMSob was not changed, indicating similar number of neuroblasts arriving to the $\mathrm{OB}$ after the lesion (Fig. 2D). The latter finding supports a previous study that showed that chemical lesion of the main OE by dichlobenil does not change cell proliferation in the SVZ (Alonso et al., 2008). The reduction in $\mathrm{OB}$ neurogenesis might result therefore from a decrease in the survival of newly generated neurons but not from a reduction in their proliferation and migration from the SVZ.
To confirm that PG neurogenesis is impaired by the chemical deafferentation, we labeled newly generated neurons by BrdU during the first week following lesion and investigate their fate 1 month after lesion by double staining with the neuronal marker NeuN. We focused our quantification to the GL where most of the adult-born neurons make direct contact with olfactory sensory inputs (Grubb et al., 2008). For long-term labeling of newly generated neurons, BrdU was administrated via the drinking water during 1 week and mice were perfused 4 weeks later (Fig. $3 A$ ), which is sufficient time for the neuroblasts produced in the SVZ to reach and integrate the $\mathrm{OB}$ circuitry (Petreanu and Alvarez-Buylla, 2002; Carleton et al., 2003). In the control group, several cells expressing both BrdU and NeuN were observed in the GL corresponding to the newly generated PG cells (Fig. 3B). We found an increased number of BrdU+ cells in the GL of the lesioned mice 1 month after the lesion (Fig. 3C). However, 

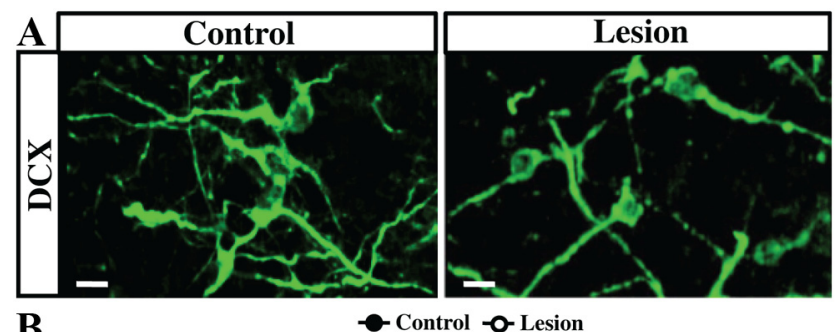

B

GL

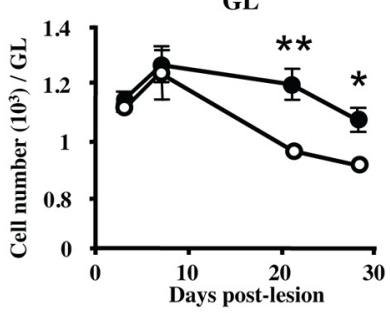

GCL
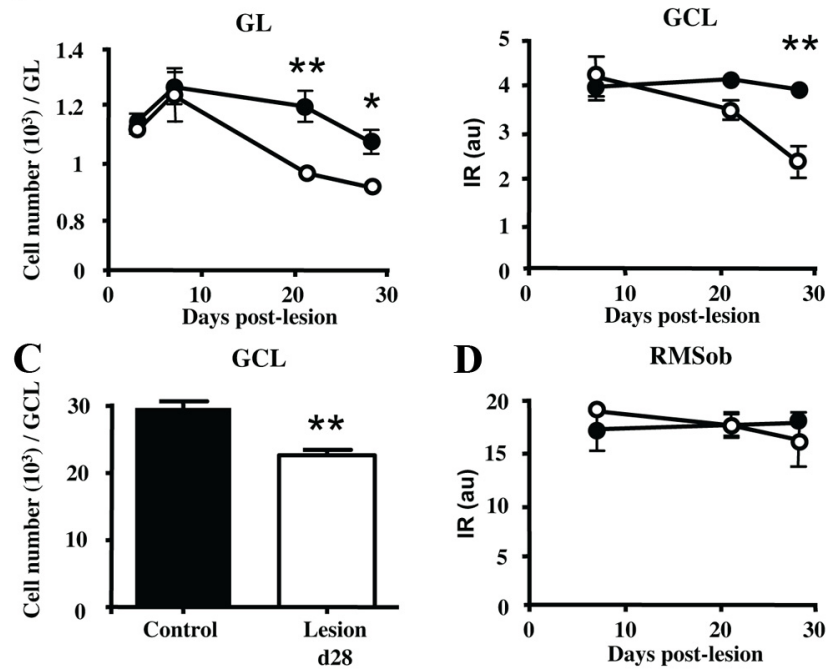

D

RMSob

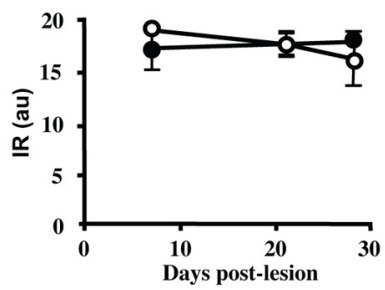

Figure 2. Sensory deafferentation decreases $O B$ adult neurogenesis. $A$, Micrographs showing projection planes of $D C X+$ neuroblasts in the $G L$ of control and deafferentated mice at 1 month after lesion. $B$, Time course of $D C X+$ neuroblasts number in the GL (left panel), or DCX immunoreactivity (optical density) in the GCL (right panel) following OE lesioning $(n=3-4)$. C, Number of DCX + cells in the GCL of control and lesioned mice at $28 \mathrm{~d}$ after lesion. D, Time course of $D C X$ immunoreactivity (optical density) in the RMSob following OE lesioning. The number of neuroblasts expressing $D C X$ is decreased at 21 and $28 \mathrm{~d}$ after lesion. ${ }^{*} p<0.05$, compared with control $(\boldsymbol{B}) ;{ }^{* *} p<0.01$, compared with control (B, C). Abbreviations: $G C L$, Granule cell layer; RMSob, the rostral migratory stream at the core of the $0 B$. Scale bar, $10 \mu \mathrm{m}$. Error bars indicate SEM.

the number of newly generated neurons (i.e., BrdU $+/ \mathrm{NeuN}+$ cells) was significantly diminished (a 45\% reduction) in the GL of lesioned mice compared with controls $\left(t_{(8)}=2.870, p=0.0208\right.$; Fig. $\left.3 C\right)$. Together, these findings support previous studies showing that sensory deprivation, or olfactory deafferentation, reduces adult $\mathrm{OB}$ neurogenesis by decreasing the survival of newly generated neurons (Corotto et al., 1994; Fiske and Brunjes, 2001; Petreanu and AlvarezBuylla, 2002; Yamaguchi and Mori, 2005; Mandairon et al., 2006; Bastien-Dionne et al., 2010; Sawada et al., 2011).

\section{Olfactory deafferentation induces microgliosis within the glomerular layer}

Because the number of BrdU + cells was relatively high in the GL $35 \mathrm{~d}$ after lesion (Fig. 3C), and since most of these cells were not neurons (i.e., NeuN-), we decided to identify the phenotype of BrdU + cells found in the GL after the lesion. Microglial proliferation (hereafter a process called microgliosis) is often observed following brain injuries; therefore, we used IBA1, a marker of both unactivated and activated microglia, to count the numbers of IBA1+ cells and IBA1+/BrdU+ cells in the GL $34 \mathrm{~d}$ after lesion (Jensen et al., 1994; Ito et al., 1998; Ajami et al., 2007). As expected, while very few IBA $1+/ \mathrm{BrdU}+$ cells were found in the normal GL, many newly generated microglial cells were observed in the GL of lesioned mice (Fig. 3D,E). Quantification showed an 18.5 -fold increase in the number of IBA $1+/ \mathrm{BrdU}+$ cells $\left(_{(5)}=\right.$
3.544; $p<0.001)$. Meanwhile, no astrocytosis was found after deafferentation (Fig. $3 F$ ). Using Olig2, a transcription factor mainly expressed by oligodendrocyte precursors and reactive astrocytes, we found no olig2 +/GFAP + cells and no change in the number of Olig2 + cells within the GL after deafferentation (data not shown), confirming that astrocytes do not proliferate after the chemical lesion (Ono et al., 2009). These findings are reminiscent of those of Graeber et al. (1988) showing a strong microgliosis but not astrocytosis following facial nerve axotomy.

Most of the new cells found in the normal GL were neurons (93\% NeuN + cells) and only $2 \%$ corresponded to newly generated IBA1 microglial cells (Fig. $3 F$ ). In contrast, in lesioned mice, $48 \%$ of new cells were NeuN + neurons and $44 \%$ were IBA1 microglial cells. Therefore, we conclude that olfactory deafferentation results in a dramatic microgliosis at the expense of the survival of adult-born PG neurons.

\section{Microgliosis occurs early after deafferentation and affects several bulbar layers}

To study the time course of deafferentation-induced microglial proliferation, BrdU was injected once $2 \mathrm{~h}$ before perfusion at 1,3 , 7, 14, 21, and $28 \mathrm{~d}$ following OE lesioning (Fig. 4A). These time points allow labeling only of local fast-proliferating cells within the OB. As expected, we found no neuronal cell expressing DCX and BrdU in the GL of healthy or lesioned mice up to 1 month (data not shown), indicating an absence of local neuronal proliferation. In contrast, several fast-proliferating IBA1 + and BrdU+ cells were found in the deafferented $\mathrm{OB}\left(t_{(6)}=7.244, p<0.001\right.$; Fig. $4 B, C)$. Microglia proliferate within $24 \mathrm{~h}$ after the lesion (treatment effect: $F_{(1,24)}=10.9, p=0.003$; Fig. $4 D$ ), peak at day $3\left(t_{(20)}=5.651 ; p<0.001\right)$, and return to baseline levels by day 7 . Microgliosis occurs in all the layers of the deafferented $O B$ at day 3, except in its core (Fig. $4 E$; treatment effect: $F_{(1,16)}=39.31, p<$ 0.001 ; layer effect: $F_{(3,16)}=18.55, p<0.001$; treatment/layer interaction: $\left.F_{(3,16)}=17.01, p<0.001\right)$. Maximal microglial proliferation was observed in the GL where OSN terminals degenerate $\left(t_{(4)}=9.170, p<0.001\right.$; Fig. $\left.4 E\right)$, while microgliosis was less pronounced in the external plexiform layer $(\mathrm{EPL})\left(t_{(4)}=4.066\right.$; $p=0.0153)$ and in the GCL $\left(t_{(4)}=3.236 ; p=0.0318\right)$. We conclude that dichlobenil administration results in a rapid and global neuroinflammation that affects all OB layers, except the RMSob, leading to a dramatic and transient fast proliferation of local microglia.

\section{Dichlobenil activates microglia in the olfactory bulb}

The microgliosis observed in the dichlobenil-treated OB suggests that microglial cells become activated by the chemical lesion. To address this question, we performed CD45 and CD68 staining (Fig. $5 \mathrm{~A}, \mathrm{C}$ ) to label the resting fraction of nonactivated microglia (low expression of these markers) and activated microglia (strong expression of both markers) (Ponomarev et al., 2005; Zattoni et al., 2011). We found numerous CD45+/IBA1 + activated microglia in the deafferented $\mathrm{OB}$ compared with the healthy $\mathrm{OB}$ (Fig. $5 A, B)$. The numbers of IBA $1+$ cells are increased in the GL at day 3 and day 34 following OE lesion (treatment effect: $F_{(2,1)}=15.37$, $\left.p=0.0007 ; 3 \mathrm{~d}: t_{(8)}=5.26, p<0.01\right)$. The number of CD45+/ IBA1+ activated microglia showed a similar time course (treatment effect: $F_{(2,9)}=11,08.18, p=0.0037 ; 3 \mathrm{~d}: t_{(8)}=4.707, p<$ $0.01)$. Activation of microglial cells was also confirmed by strong staining for CD68 in the deafferented OB 1 month after lesion (Fig. 5C). BrdU was injected $2 \mathrm{~h}$ before perfusion to label fastproliferating microglia. Three days after OE lesion, nearly all BrdU + cells in the GL also express CD68 (Fig. 5C), showing they 

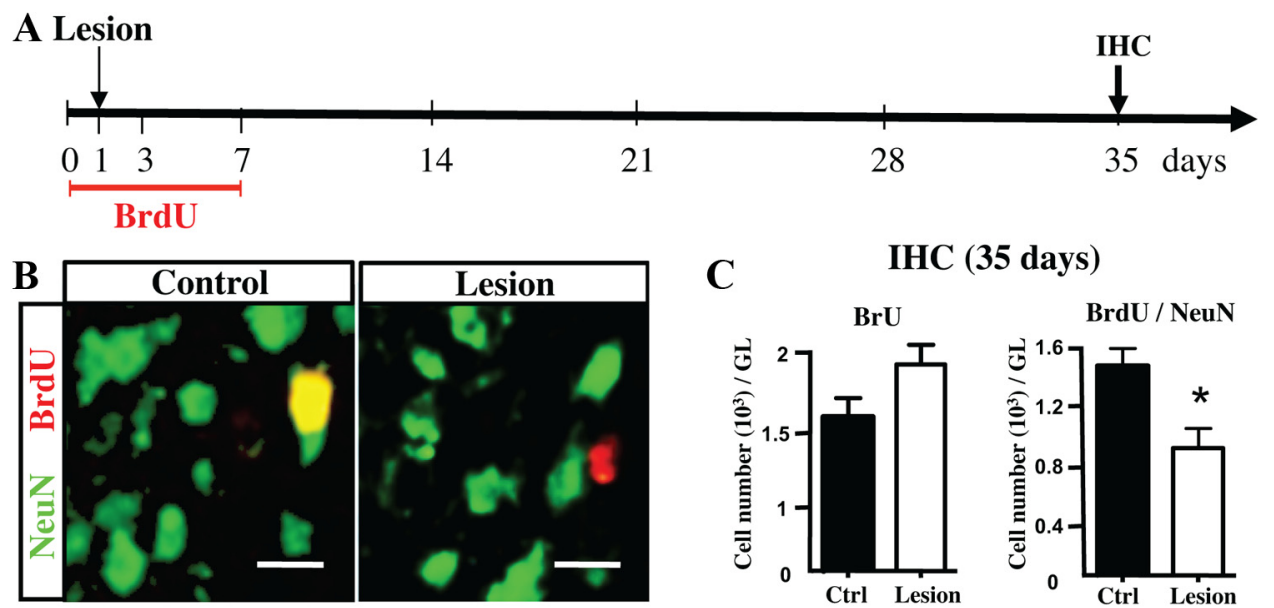

C IHC (35 days)
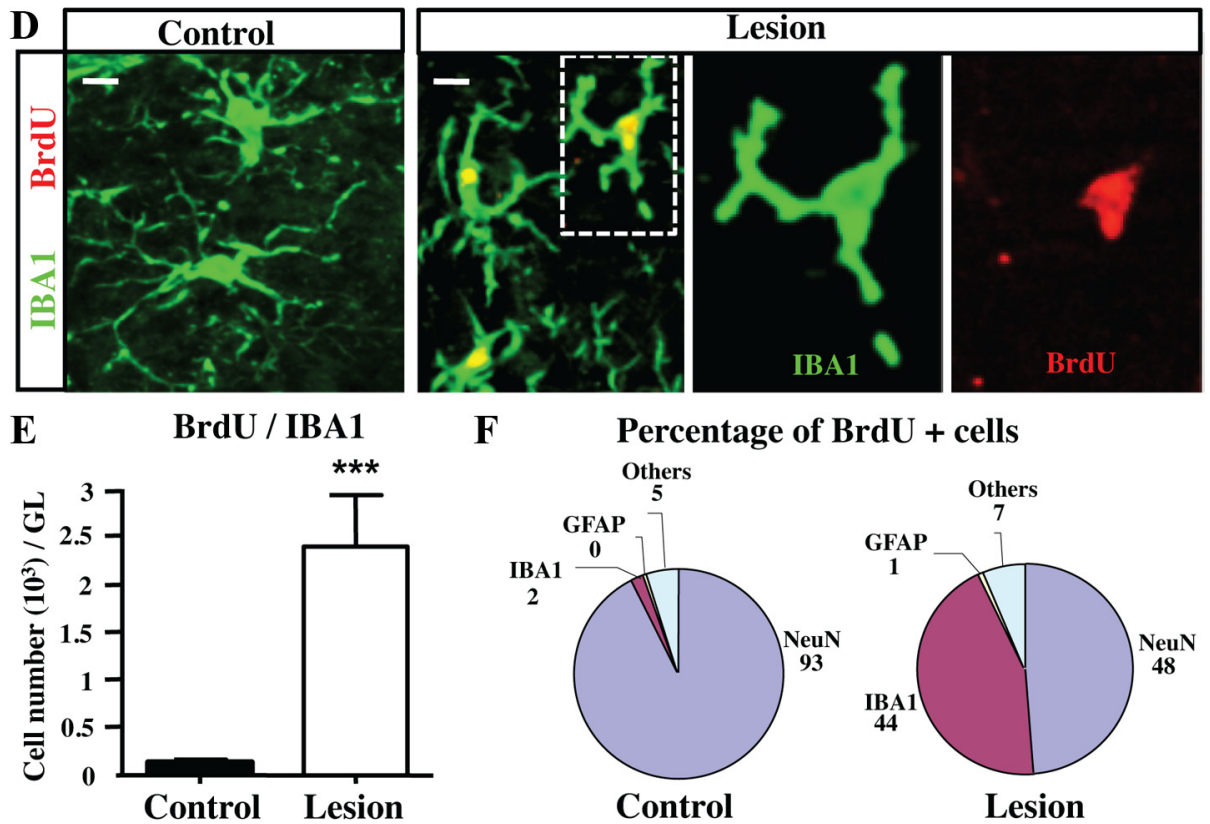

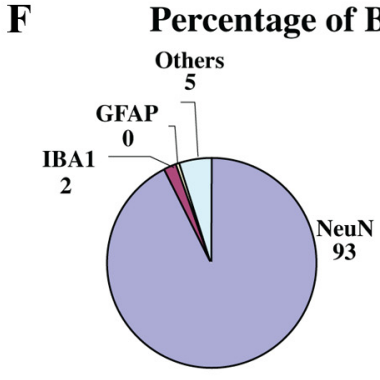

Control

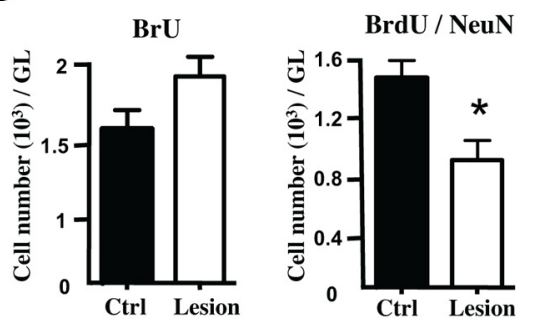

Figure 3. Sensory deafferentation reduces the number of newly generated neurons but increases the number of microglial cells in the GL. $\boldsymbol{A}$, Experimental design. To label all proliferating cells, BrdU was given in the drinking water during 1 week, beginning $1 \mathrm{~d}$ before 0 E lesion. The latter was performed $1 \mathrm{~d}$ after starting BrdU administration, and the $0 \mathrm{Bs}$ were collected at $35 \mathrm{~d}$ for subsequent immunohistochemistry (IHC). B, Apotome micrographs showing BrdU + /NeuN + double-positive (yellow) new neurons, BrdU + new cells (red), and NeuN + neurons (green) in the GL of control and deafferentated mice, at $35 \mathrm{~d}$ after lesion. Images represent a single optical plane. $\boldsymbol{C}$, BrdU + and BrdU $+/ \mathrm{NeuN}+$ cell numbers in the $\mathrm{GL}$ of control and deafferentated mice, at $35 \mathrm{~d}$ ( $n=4-6$ ). The number of new neurons expressing both BrdU and NeuN is strongly reduced in lesioned mice. D. Cellular colocalization of IBA1 (green) with BrdU (red) analyzed in the GL at $35 \mathrm{~d}$ after lesion. Higher magnification of one BrdU + microglia (dotted lines) was shown in both red and green channels (single plane). $\boldsymbol{E}$, Number of BrdU $+/ I B A 1+$ double-labeled new microglial cells in the GL $35 \mathrm{~d}$ after OE lesion $(n=3-4)$. F, Percentage of BrdU + cells colabeled with one of three antigenically identified cell populations, GFAP + astrocytes, NeuN + neurons, and IBA1 + microglial cells, in the $\mathrm{GL}$ of control and lesioned mice at $35 \mathrm{~d}$ after lesion $(n=3-4) .{ }^{*} p<0.05$, compared with control $(\boldsymbol{C}) ;{ }^{* * *} p<0.001$, compared with control $(\boldsymbol{E})$. Scale bar, $10 \mu \mathrm{m}$. Error bars indicate SEM.

represent activated and proliferating microglia. The number of CD68-expressing cells is strongly increased in the GL at day 3 following OE lesion $\left(t_{(4)}=17.06, p<0.0001\right.$; Fig. 5D). CD68 immunoreactivity was increased in the olfactory nerve layer $(\mathrm{ON}), \mathrm{GL}$, and GCL at day 3, day 7, and day 34 after lesion (treatment effect: $F_{(3,33)}=28.94, p<0.0001$; ON at $3 \mathrm{~d}: t_{(6)}=$ 7.058, $p<0.001$; GL at $3 \mathrm{~d}: t_{(6)}=5.598, p<0.001$; GCL at $3 \mathrm{~d}: t_{(6)}$ $=2.629, p<0.05$; Fig. $5 E)$. Particularly the number of CD68+/ $\mathrm{BrdU}+$ cells is strongly increased in the GL at day 3 following OE lesion $\left(t_{(4)}=17.44, p<0.0001\right.$; Fig. $\left.5 F\right)$. Both CD45 and CD68 staining indicate that maximal microglial activation occurred promptly following the lesion and lasted at least 1 month. Therefore, we conclude that microglia rapidly respond to olfactory deafferentation by transiently undergoing both proliferation and activation in the $\mathrm{OB}$ circuit.
Antiinflammatory treatment blocks the proliferation and activation of microglia

Peripheral immune cells such as T-cells are required during adulthood for the regulation of proliferation and differentiation of certain stem cells, as demonstrated for the regeneration of hepatocytes from liver stem cells after liver damage (Strick-Marchand et al., 2008). Similarly, T-lymphocytes and microglia are required for the activitydependent modulation of hippocampal neurogenesis and spatial learning abilities in adulthood (Ziv et al., 2006). We thus compared the microglial response of immunocompetent (control) and immunodeficient mice after deafferentation (Fig. 6A). For this, we used Rag2 $\gamma^{-1-}$ mice, which lack T-cells, B-cells, and natural killer cells (Colucci et al., 1999). These alymphoid mice have about the same content of microglial cells as control mice (data not shown). BrdU was injected once $2 \mathrm{~h}$ before perfusion to label fast-proliferating cells, 


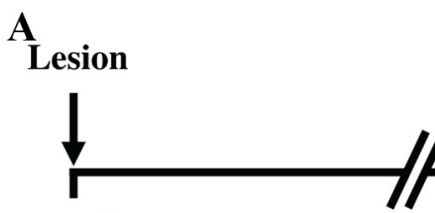

Day 0
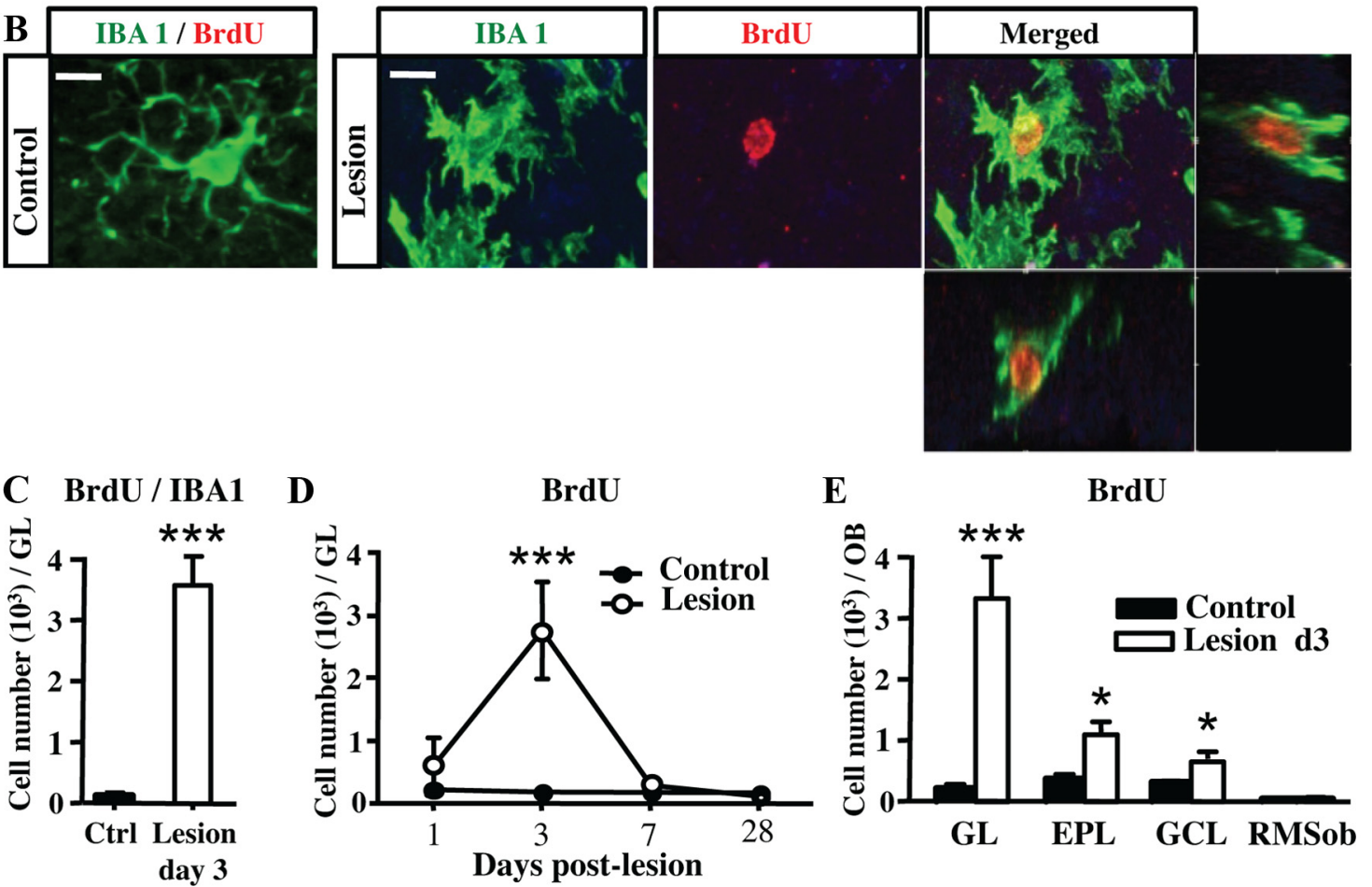

Figure 4. Microglial cells proliferate swiftly in the $\mathrm{OB} 3 \mathrm{~d}$ after lesion. $A$, Design of the experiments. To label fast-proliferating cells, BrdU was injected $2 \mathrm{~h}$ before perfusion. The $0 \mathrm{~B}$ was collected at day $1,3,7$, and 28 following 0 E lesioning. B, Cellular colocalization of IBA1 (green) with BrdU (red) analyzed in the GL at $3 \mathrm{~d}$ after lesion. Images shown represent the maximal projections of the merged channel (control, left; lesion, right) of each individual channel, and the orthogonal analysis in a single optical plane (lesion, far right). In contrast to control mice, several BrdU + cells are present in the $\mathrm{GL}$ of lesioned mice at $3 \mathrm{~d}$ after lesion. Nearly all BrdU + cells are IBA1 +. C, Number of BrdU + /IBA1 + cells located in the GL at $3 \mathrm{~d}$ after lesion ( $n=4$ per group). $\boldsymbol{D}$, Time course of $\mathrm{BrdU}+$ cells in the $\mathrm{GL}(n=4$ per group). Fast proliferation peaks at day 3 after lesion and resumes $4 \mathrm{~d}$ later. $E$, Number of BrdU + cells located in the GL, EPL, GCL, and RMSob at $3 \mathrm{~d}$ after lesion ( $n=$ 3 per group). Fast cell proliferation occurs in all OB layers. ${ }^{*} p<0.05$, compared with control (D); ${ }^{* * *} p<0.001$, compared with control $(\boldsymbol{C}, \boldsymbol{D})$. Scale bar (applied to all $\boldsymbol{B}$ pictures): $10 \mu \mathrm{m}$. Error bars indicate SEM.

and the microgliosis was assessed by quantifying BrdU+ cells. Olfactory deafferentation in alymphoid mice resulted in similar microgliosis within the $\mathrm{OB}$ at day 3 (Fig. $6 \mathrm{~A}$; comparison between controls and lesioned alymphoid mice: $t_{(4)}=6.102, p<0.001$, and $t_{(6)}=$ $0.6358, p>0.05)$. These data clearly establish that the adaptive immune system is not required for microglial responses after sensory deafferentation.

Then, we investigated the effect of a nonsteroid antiinflammatory drug, minocycline, on the microglial reactivity (proliferation and activation) induced by the lesion (Fig. $6 A, B$ ). Minocycline is an antibiotic, which has been reported to inhibit microglial activation in several acute or chronic brain insults (Yrjänheikki et al., 1998; Tikka et al., 2001a; Ekdahl et al., 2003). We found that, $3 \mathrm{~d}$ after $\mathrm{OE}$ lesion, minocycline treatment blocked the cell proliferation seen in the GL (Fig. 6A; comparison between nontreated and minocycline-treated lesioned mice: $\left.t_{(6)}=6.102, p<0.05\right)$. At the same time, minocycline treatment strongly reduced CD68 immunoreactivity, indicating reduced neuroinflammation in the OB (minocycline effect: $F_{(1,8)}=7.33, p=0.0268$; Fig. $6 B$ ). Microglial activation was also suppressed by minocycline in the GL and GCL of deafferented mice (minocycline effect for GL: $F_{(1,8)}=$ 8.03, $p=0.022$; minocycline effect for GCL: $F_{(1,8)}=7.39, p=$
0.0263; Fig. 6B). Thus, lesion-induced activation and proliferation of microglia is sensitive to our antiinflammatory treatment.

Antiinflammatory treatment promotes the survival of adult-born neurons

Given the broad inhibitory effects of minocycline on the lesioninduced neuroinflammation in the $\mathrm{OB}$, we investigated first whether daily minocycline treatment might restore olfaction and the $\mathrm{OB}$ activity after the chemical lesion (Fig. $7 A, B$ ). No difference was found in the mean latency in the buried food finding test between lesioned mice and minocycline-treated lesioned mice (Fig. 7A). Furthermore, we found that the TH expression in the GL was similarly reduced in lesioned mice that received minocycline treatment compared with controls (minocycline effect: $F_{(1,13)}=0.12, p=0.7398$; Fig. $7 B$ ). These findings indicate that minocycline efficiently prevents microglial proliferation in response to the lesion without altering the severity of the lesion itself.

The decreased survival of adult-born neurons seen after OE lesion might result from a reduction in the neuronal activity in the deafferented $\mathrm{OB}$ and/or to a deleterious context promoted by the activated microglia. To address this issue, minocycline was administrated daily during 1 month following OE lesion, and DCX 
A
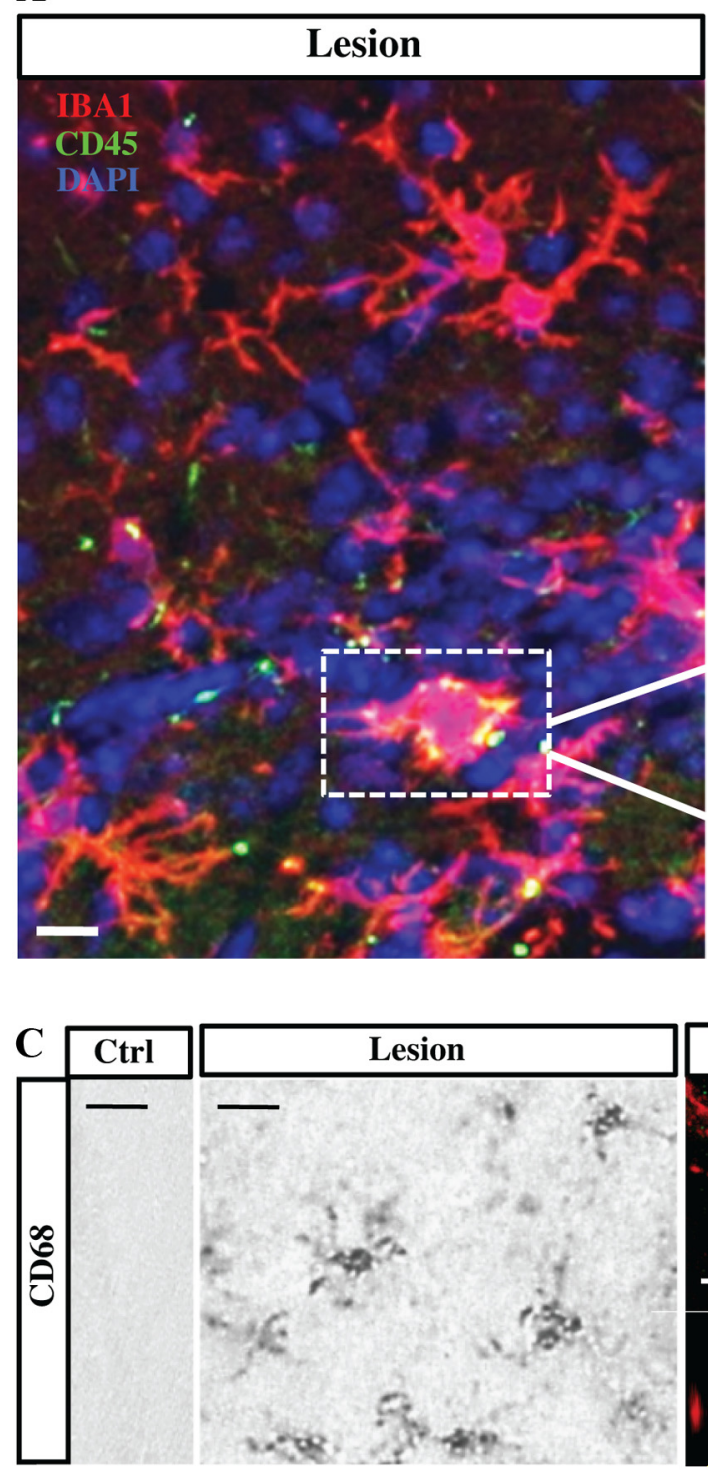

E

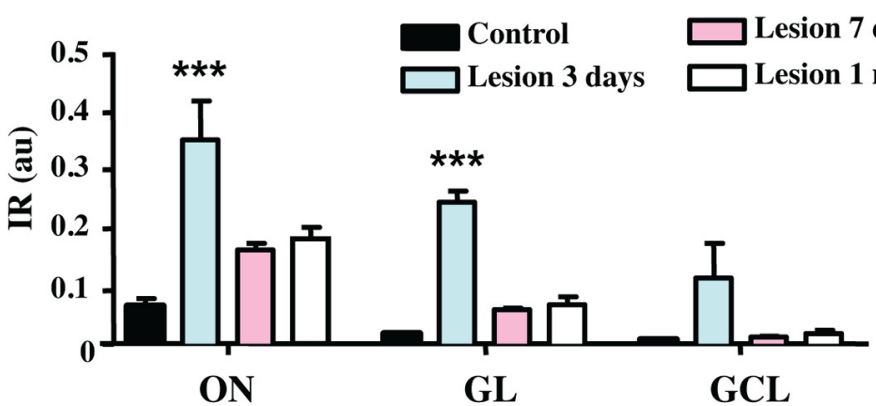

B
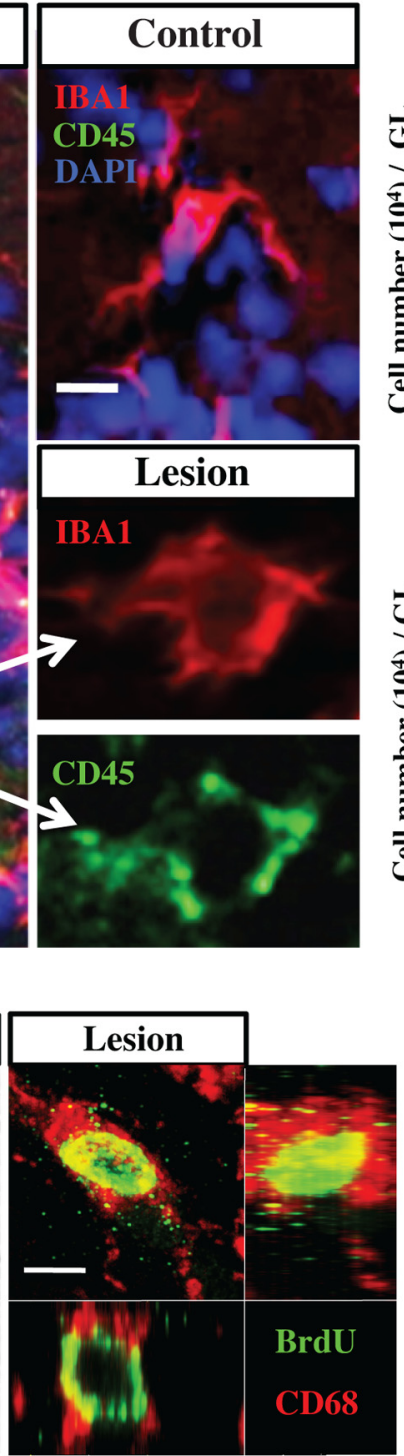

D

CD68

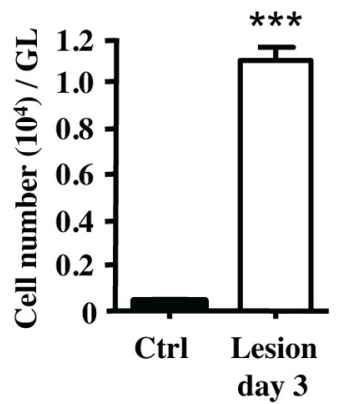

F

BrdU / CD68

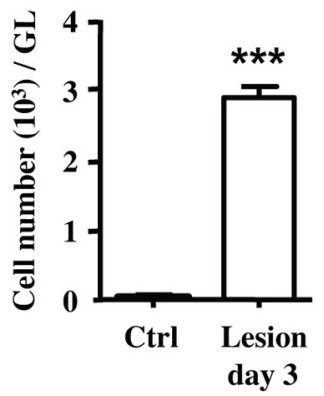

Figure 5. Microglial cells are activated by deafferentation. $A$, Confocal pictures showing IBA1+/CD45 + (yellow) activated microglia, IBA1 + microglia (red), and CD45 + (green) cells in the GL of control and deafferentated mice, at day 3. Images shown represent a single optical plane. Higher magnification of one activated microglia (dotted lines) was shown in both red and green channels. B, Number of IBA1 + cells and IBA1+/CD45 + cells in the GL at 3 and $34 \mathrm{~d}$ after lesion $(n=6-4)$. C, Immunohistochemical staining of CD68 + activated microglia in the GL of control (left) and deafferentated (middle) mice at $3 \mathrm{~d}$ after lesion. Cellular colocalization of CD68 (red) with BrdU (green) analyzed in the $\mathrm{GL}$ at $3 \mathrm{~d}$ after lesion (right). BrdU was injected $2 \mathrm{~h}$ before perfusion. $D$, Number of $\mathrm{CD} 68+$ cells in the $\mathrm{GL}$ at $3 \mathrm{~d}$ after lesion $(n=3-4)$. E, Densitometric analysis of CD68 immunoreactivity in the olfactory nerve (ON), $\mathrm{GL}$, and $\mathrm{GCL}, 3 \mathrm{~d}, 7 \mathrm{~d}$, or 1 month after lesion $(n=3-4)$. $\boldsymbol{D}$, Number of BrdU +/CD68 + cells in the GL at 3 d after lesion $(n=3-4)$. Data in $\boldsymbol{B}, \boldsymbol{D}$, and $\boldsymbol{F}$ are number of cells counted in the $\mathrm{GL}$ expressed per whole $0 \mathrm{~B}$. ${ }^{* *} p<0.01$, compared with control $(\boldsymbol{B})$; ${ }^{* * *} p<0.001$, compared with control (D-F). Scale bars: $A, 10 \mu \mathrm{m} ; \boldsymbol{C}$, right, middle, $30 \mu \mathrm{m}$; left, $10 \mu \mathrm{m}$. Error bars indicate SEM. 
immunostaining was performed in the $\mathrm{OB}$ to quantify the number of immature adultborn neurons (Fig. 7C). We found no difference in DCX immunoreactivity in the RMSob of all mice treated with or without minocycline (Fig. 7D). These data indicate that minocycline administration does not change the number of neuroblasts reaching the $\mathrm{OB}$ after deafferentation. Conversely, we found that minocycline treatment promotes the survival of DCX + neuroblasts in the GL after deafferentation since the number of DCX+ cells increased in minocycline-treated mice compared with controls (Fig. $7 D$; minocycline effect: $F_{(1,14)}$ $=4.85, p=0.0449$ ). A similar effect of minocycline was also observed in the GCL of deafferented mice (Fig. 7C,D; minocycline effect: $\left.F_{(1,13)}=8.14, p=0.0281\right)$. Thus, antiinflammatory treatment prevents the massive loss of newly formed GC and PG cells induced by the sensory deafferentation, despite the strong reduction of sensory afferents to the $\mathrm{OB}$.

\section{Discussion}

In this study, we identify activated microglia, rather than the lack of sensory experience, as a powerful effector of adult $\mathrm{OB}$ neurogenesis. We show that partial ablation of sensory afferents results in the transient proliferation and activation of microglial cells that shorten the life span of adult-born neurons. Preventing microglial activation by antiinflammatory treatment restores the survival of the adult-born neurons despite maintenance of the sensory deafferentation. These results demonstrate that activated microglial cells play key role in regulating the survival of adult-born neurons.

\section{Microglial cells mediate innate immune response}

Microglia are critically involved not only in inflammatory and immune responses during brain diseases or trauma but also in the healthy developing brain (Paolicelli et al., 2011; Prinz et al., 2011; Chung and Barres, 2012). While microglia regulate the number of neuroblasts during developmental neurogenesis in the cerebellum, several lines of evidence suggest that microglia also regulate early steps of the adult neurogenesis (Marín-Teva et al., 2004). First, microglia eliminate dying neuroblasts within the neurogenic niche of the adult hippocampus (Sierra et al., 2010). Second, activated microglia impair the formation of new neurons in the adult hippocampus (Ekdahl et al., 2003; Monje et al., 2003). For instance, irradiation damages the proliferative niche in the adult hippocampus by activating microglia cells and triggering aberrant angiogenesis that collectively lead to sustained blockade of neurogenesis (Monje et al., 2003). Third, quiescent microglia also contribute to regulating adult neurogenesis. Under basal conditions, apoptotic corpses of newly generated neurons are rapidly eliminated from their place of birth, in the adult subgranular zone, by unactivated microglia endowed with intense phagocytic activity (Sierra et al., 2010). Our results complement these findings by showing that activated microglia also contribute to adult neurogenesis by acting on a more distal parameter of the adult neurogenesis: the survival rate of immature adult-born neurons.

We show here that dichlobenil-induced olfactory deafferentation leads to a massive cell death of OSNs innerving the OB. The degeneration of sensory terminals within glomeruli induces local microglial activation through an innate immune response that likely involves activation of microglial pattern receptors known to recognize endogenous molecules (DNA, proteins, etc.), as yet unidentified and released by damaged cells. It is important to note that this robust immune response is maintained as an active state in the healthy OB due to the ongoing replacement of OSNs and of their OB neuronal counterparts, throughout life (Schwob, 2002; Lledo and Gheusi, 2003). As a result, the adult olfactory system is a site of high cell apoptosis, both at the sensory organ and the first central relay where new PG and GCs are continuously replaced (Lledo et al., 2005). Approximately one-half of the thousands of new interneurons that reach the $\mathrm{OB}$ each day die in the first month after their birth (Petreanu and Alvarez-Buylla, 2002). In nonlesioned mice, local microglia might contribute to the clearance of OSN cellular debris within the glomeruli, as well as the elimination of dying new PG cells, leading to the activation of a small proportion of microglia in the healthy mice (Fig. 5). This suggests that (1) dying adult-born $\mathrm{OB}$ neurons in the healthy $\mathrm{OB}$ circuit do not substantially activate microglia, and (2) the continuous turnover of adult-born $\mathrm{OB}$ neurons does not depend on the activation state of microglia, although we cannot rule out that a low level of activation may be sufficient to clear normal levels of apoptosis. In contrast to our finding, it is noteworthy that substantial numbers of activated microglia have been reported in the developing OB (Fiske and Brunjes, 2000). Postnatal development is a period of broad neurogenesis within the $\mathrm{OB}$, with precise pruning of excess neurons to allow correct tuning of neuronal circuits. Thus, we propose that apoptosis in the developing $\mathrm{OB}$ 


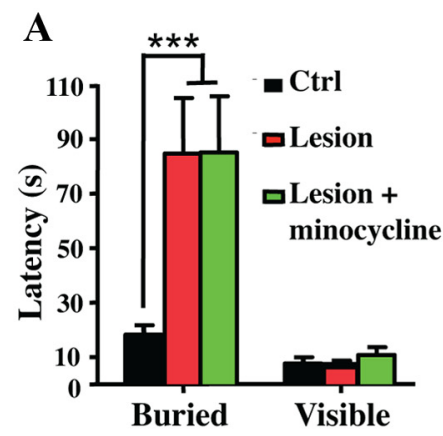

Buried food finding

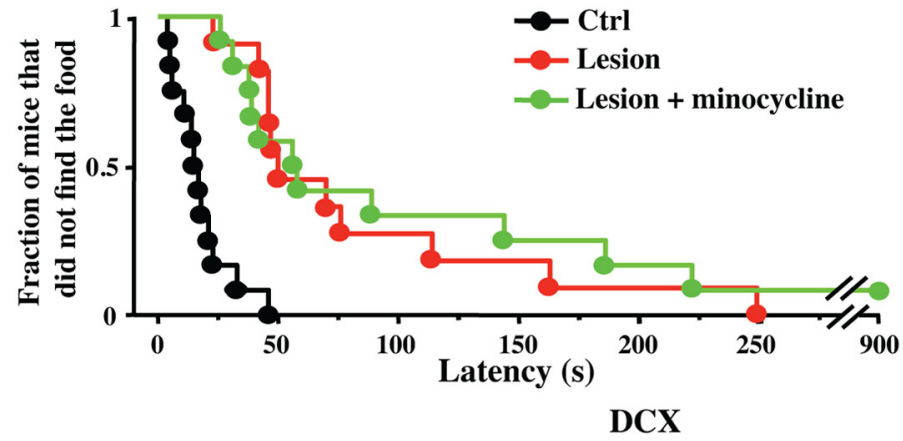

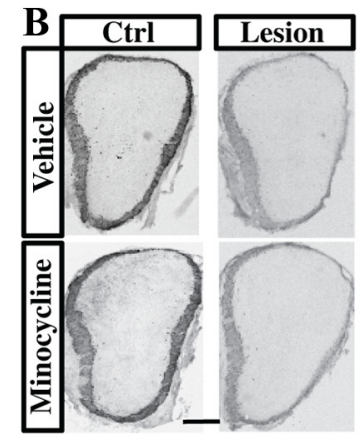

D

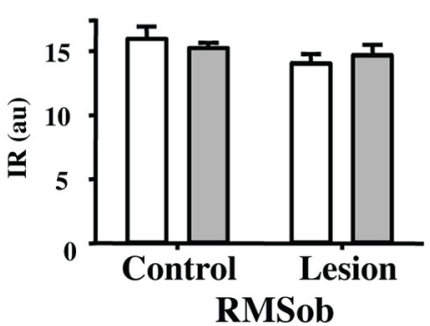

TH

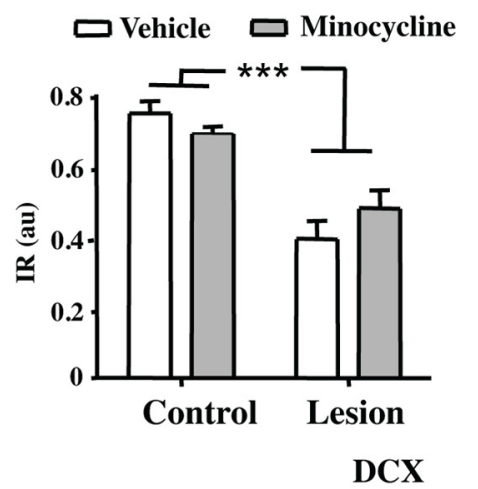

C
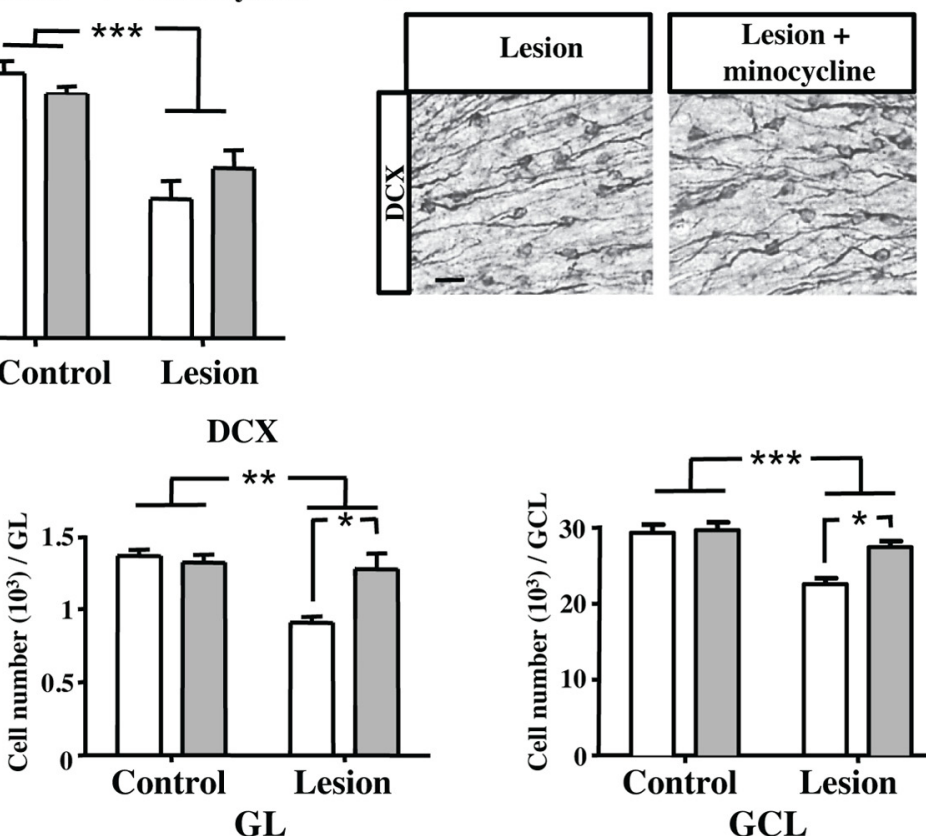

Figure 7. Minocycline restores $0 B$ neurogenesis but not sensory inputs in lesioned mice. $A$, Latency to find the buried or visible food in the buried food-finding test performed at $26 \mathrm{~d}$ ( $n=11-12$ ) after lesion. Results are mean of latency to feed in seconds (left) or fraction of mice that did not find the hidden food over 15 min (right). $\boldsymbol{B}$, Pictures of $0 B$ coronal sections showing TH immunoreactivity in the $\mathrm{GL}$ of control and deafferentated mice, 1 month after lesion, in vehicle-treated and minocycline-treated mice. Quantification of TH immunoreactivity in the GL of control and deafferented mice at 1 month after lesion in vehicle-treated and minocycline-treated mice $(n=4-5)$. Minocycline treatment does not restore the TH expression level in the GL following deafferentation. C, DCX immunostaining in the GCL of mice at 1 month after deafferentation, with (right) and without (left) minocycline treatment. $D$, Quantification of DCX immunoreactivity by densitometry in the RMSob, and DCX cell number in the $\mathrm{GL}$ and $\mathrm{GCL}$ of the $0 \mathrm{~B}$ at 1 month after 0 E lesioning, with (gray) and without minocycline (white) treatment ( $n=4-5$ ). ${ }^{*} p<0.05$, compared with vehicle $(\boldsymbol{D})$; ${ }^{* *} p<0.01$, compared with control $(\boldsymbol{D}) ;{ }^{* * *} p<0.01$, compared with control $(\boldsymbol{A}, \boldsymbol{B}, \boldsymbol{D})$. Scale bars: $\boldsymbol{A}, 200 \mu \mathrm{m} ; \boldsymbol{B}, 20 \mu \mathrm{m}$. Error bars indicate SEM.

activates local microglia that, in turn, play a key role for neuronal survival in a similar manner as reported for the developing cerebellum (Marín-Teva et al., 2004). Another interesting possibility is that excess "nondying" neurons express factors that attract and activate microglia, which in turn eliminate them, perhaps by inducing an apoptotic cascade or by the action of cytokines such as the tumor necrosis factor, or by nitric oxide, and reactive oxygen species. In the near future, further investigations will certainly identify the nature of inflammatory mediators released by activated microglia during the innate immune response.

Microglial activation is the main hallmark of neuroinflammation and often results in secondary astrocyte activation and recruitment of leukocytes within the parenchyma, depending on the degree and duration of the insult (Prinz et al., 2011). We found no astrocyte proliferation (Fig. 3) but rather an upregulation of the GFAP expression level (assessed by immunohistochemistry) (data not shown), which reflects moderate astrocyte activation. Microglial reaction oc- curs not only in the GL but also elsewhere in the bulb, suggesting a significant diffusion of microglia-activating factors first from the GL and then to all layers. Moreover, no leukocyte infiltration was observed within the OB following the lesion (data not shown), confirming that the neuroinflammation induced by deafferentation is moderate and transient. Because we found no infiltration of leukocytes into the deafferented $\mathrm{OB}$, the hypothesis of the microglial replenishment by macrophages, or precursors originating outside of the CNS, can be discarded. Microglia are probably renewed and activated in situ as previously shown using a parabiosis method (Ajami et al., 2007).

\section{Tuning the survival of adult-born neurons during OB inflammation}

The number of new neurons residing in the $\mathrm{OB}$ is dramatically reduced by olfactory deafferentation. Previous studies have shown that adult neurogenesis is reduced by a broad inflammation resulting 
from systemic injection of proinflammatory factors or by local inflammation of the SVZ (Carpentier and Palmer, 2009; Tepavčević et al., 2011). In all cases, the reduction in the number of new OB neurons reflects the decreased production of neuroblasts by the inflamed SVZ, as previously found in the hippocampus (Monje et al., 2003). Our results demonstrate that local inflammation within the $\mathrm{OB}$ alters the survival of newly formed neurons and not their recruitment to the bulb, per se. We found also that minocycline treatment inhibits both microglial proliferation and activation in lesioned mice, supporting the strong antiinflammatory effect of this drug (Yrjänheikki et al., 1998; Tikka et al., 2001a; Ekdahl et al., 2003). Minocycline is a potent inhibitor of microglial activation in vitro and in vivo, which dramatically decreases the activation of microglial $\mathrm{NADPH}$-oxidase and the microglial production of proinflammatory cytokines and inducible nitric oxide synthase (Tikka and Koistinaho, 2001; Tikka et al., 2001b; Wu et al., 2002; Hutchinson et al., 2008). Inhibition of microglial activation using minocycline probably results from the blockage of cyclooxygenase- 2 induction and the activation of stress-activated p38 mitogen-activated protein kinase, two key enzymes involved in the production of proinflammatory prostanoids, proinflammatory cytokines, and cytotoxic molecules including reactive oxygen species and nitric oxide (Yrjänheikki et al., 1999; Tikka et al., 2001a). The neuroprotective effects of minocycline are probably attributable to the suppression of proinflammatory cytokines and nitric oxide-mediated neurotoxicity (Du et al., 2001). Of course, one cannot rule out the possibility that at least some of the neuroprotection of minocycline results from a direct action on neurons as previously proposed (Domercq and Matute, 2004). Of note, minocycline treatment does not suppress OSN degeneration induced by dichlobenil treatment and thus does not rescue sensory inputs to the $\mathrm{OB}$ (Fig. $7 A, B$ ). Conversely, minocycline administration rescues adult-born neurons that otherwise would die after olfactory deafferentation (Fig. 7D). These findings support a role of activated microglia in promoting the death of maturing newly formed neurons. Thus, a simple systemic, nonsteroid antiinflammatory treatment is sufficient to promote neuronal survival in the context of local inflammation.

Two conclusions can be drawn from our antiinflammatory treatment. First, minocycline administration to nonlesioned mice does not perturb the baseline level of neuronal survival, indicating that the moderate activation of microglia in the healthy OB does not participate in the continuous turnover of adult-born neurons. Second, minocycline treatment does not change the amount of neuroblasts reaching the $\mathrm{OB}$, indicating that minocycline does not affect the SVZ production of neuroblasts. This finding extends previous results showing that odorant deprivation, or olfactory deafferentation, leads to a decreased survival of new OB neurons (Corotto et al., 1994; Petreanu and Alvarez-Buylla, 2002; Yamaguchi and Mori, 2005; Mandairon et al., 2006; Bastien-Dionne et al., 2010; Sawada et al., 2011). From the present study, we conclude that activated microglia is a key regulator capable of adjusting the survival of maturing adultborn $\mathrm{OB}$ neurons, at least following chemical lesion of the sensory afferents.

For the first time, our study demonstrates that the targets of this deafferentation are the DCX + neurons, suggesting that microglia mostly eliminate developing young neurons. It is possible that activated microglia require caspases to eliminate the newly formed cells. If this hypothesis holds true for the adult OB neurogenesis, the finding that activated microglia operate preferentially on maturing adult-born neurons is consistent with a recent demonstration that immature neurons die mostly under caspase-dependent mechanisms between the age of 14 and $20 \mathrm{~d}$ (Yokoyama et al., 2011). Further studies are necessary to precisely identify the time win- dow(s) during which microglia selectively eliminate maturing neurons. Interestingly, microglia activation largely precedes the decrease in neuronal survival, which first begins in the GL and later in the GCL. This delay might result from the propagation of olfactory processing impairment from glomeruli to deeper OB layers. Further clarification of the mechanisms by which microglia eliminate the neuroblasts should shed light on the complex dynamics of the OB neuronal turnover.

Numerous studies have demonstrated that OB neuronal survival is activity dependent and that synaptic activity plays a crucial role in cell death/survival decisions (Lazarini and Lledo, 2011). New neurons selected to die following the loss of sensory activity could be tagged for subsequent elimination by activated microglia. In this context, inhibition of microglia would ensure the survival of these tagged neurons. Our study demonstrates that microglial cells, known to remove dead cells by phagocytosis, may also promote the death of $\mathrm{OB}$ neuroblasts under inflammatory conditions. Collectively, these findings, beyond their basic biological interest, open new therapeutic perspectives on potential antiinflammatory, proneurogenic interventions aimed at improving neuronal survival in both the healthy and diseased brain.

\section{References}

Ajami B, Bennett JL, Krieger C, Tetzlaff W, Rossi FM (2007) Local selfrenewal can sustain CNS microglia maintenance and function throughout adult life. Nat Neurosci 10:1538-1543.

Alonso M, Ortega-Pérez I, Grubb MS, Bourgeois JP, Charneau P, Lledo PM (2008) Turning astrocytes from the rostral migratory stream into neurons: a role for the olfactory sensory organ. J Neurosci 28:11089-11102.

Baker H, Kawano T, Margolis FL, Joh TH (1983) Transneuronal regulation of tyrosine hydroxylase expression in olfactory bulb of mouse and rat. J Neurosci 3:69-78.

Bastien-Dionne PO, David LS, Parent A, Saghatelyan A (2010) Role of sensory activity on chemospecific populations of interneurons in the adult olfactory bulb. J Comp Neurol 518:1847-1861.

Brown JP, Couillard-Després S, Cooper-Kuhn CM, Winkler J, Aigner L, Kuhn HG (2003) Transient expression of doublecortin during adult neurogenesis. J Comp Neurol 467:1-10.

Carleton A, Petreanu LT, Lansford R, Alvarez-Buylla A, Lledo PM (2003) Becoming a new neuron in the adult olfactory bulb. Nat Neurosci 6:507-518.

Carpentier PA, Palmer TD (2009) Immune influence on adult neural stem cell regulation and function. Neuron 64:79-92.

Chung WS, Barres BA (2012) The role of glial cells in synapse elimination. Curr Opin Neurobiol. Advance online publication. doi:10.1016/j.conb.2011.10.003.

Clelland CD, Choi M, Romberg C, Clemenson GD Jr, Fragniere A, Tyers P, Jessberger S, Saksida LM, Barker RA, Gage FH, Bussey TJ (2009) A functional role for adult hippocampal neurogenesis in spatial pattern separation. Science 325:210-213.

Colucci F, Soudais C, Rosmaraki E, Vanes L, Tybulewicz VL, Di Santo JP (1999) Dissecting NK cell development using a novel alymphoid mouse model: investigating the role of the c- $a b l$ proto-oncogene in murine NK cell differentiation. J Immunol 162:2761-2765.

Corotto FS, Henegar JR, Maruniak JA (1994) Odor deprivation leads to reduced neurogenesis and reduced neuronal survival in the olfactory bulb of the adult mouse. Neuroscience 61:739-744.

Domercq M, Matute C (2004) Neuroprotection by tetracyclines. Trends Pharmacol Sci 25:609-612.

Du Y, Ma Z, Lin S, Dodel RC, Gao F, Bales KR, Triarhou LC, Chernet E, Perry KW, Nelson DL, Luecke S, Phebus LA, Bymaster FP, Paul SM (2001) Minocycline prevents nigrostriatal dopaminergic neurodegeneration in the MPTP model of Parkinson's disease. Proc Natl Acad Sci U S A 98: 14669-14674.

Ekdahl CT, Claasen JH, Bonde S, Kokaia Z, Lindvall O (2003) Inflammation is detrimental for neurogenesis in adult brain. Proc Natl Acad Sci U S A 100:13632-13637.

Fiske BK, Brunjes PC (2000) Microglial activation in the developing rat olfactory bulb. Neuroscience 96:807-815. 
Fiske BK, Brunjes PC (2001) Cell death in the developing and sensorydeprived rat olfactory bulb. J Comp Neurol 431:311-319.

Genter MB, Owens DM, Carlone HB, Crofton KM (1996) Characterization of olfactory deficits in the rat following administration of 2,6dichlorobenzonitrile (dichlobenil), 3,3'-iminodipropionitrile, or methimazole. Fundam Appl Toxicol 29:71-77.

Ginhoux F, Greter M, Leboeuf M, Nandi S, See P, Gokhan S, Mehler MF, Conway SJ, Ng LG, Stanley ER, Samokhvalov IM, Merad M (2010) Fate mapping analysis reveals that adult microglia derive from primitive macrophages. Science 330:841-845.

Graeber MB, Tetzlaff W, Streit WJ, Kreutzberg GW (1988) Microglial cells but not astrocytes undergo mitosis following rat facial nerve axotomy. Neurosci Lett 85:317-321.

Grubb MS, Nissant A, Murray K, Lledo PM (2008) Functional maturation of the first synapse in olfaction: development and adult neurogenesis. J Neurosci 28:2919-2932.

Hutchinson MR, Northcutt AL, Chao LW, Kearney JJ, Zhang Y, Berkelhammer DL, Loram LC, Rozeske RR, Bland ST, Maier SF, Gleeson TT, Watkins LR (2008) Minocycline suppresses morphine-induced respiratory depression, suppresses morphine-induced reward, and enhances systemic morphine-induced analgesia. Brain Behav Immun 22:1248-1256.

Imayoshi I, Sakamoto M, Ohtsuka T, Takao K, Miyakawa T, Yamaguchi M, Mori K, Ikeda T, Itohara S, Kageyama R (2008) Roles of continuous neurogenesis in the structural and functional integrity of the adult forebrain. Nat Neurosci 11:1153-1161.

Ito D, Imai Y, Ohsawa K, Nakajima K, Fukuuchi Y, Kohsaka S (1998) Microglia-specific localisation of a novel calcium binding protein, Ibal. Brain Res Mol Brain Res 57:1-9.

Jakubs K, Bonde S, Iosif RE, Ekdahl CT, Kokaia Z, Kokaia M, Lindvall O (2008) Inflammation regulates functional integration of neurons born in adult brain. J Neurosci 28:12477-12488.

Jamain S, Radyushkin K, Hammerschmidt K, Granon S, Boretius S, Varoqueaux F, Ramanantsoa N, Gallego J, Ronnenberg A, Winter D, Frahm J, Fischer J, Bourgeron T, Ehrenreich H, Brose N (2008) Reduced social interaction and ultrasonic communication in a mouse model of monogenic heritable autism. Proc Natl Acad Sci U S A 105:1710-1715.

Jaskelioff M, Muller FL, Paik JH, Thomas E, Jiang S, Adams AC, Sahin E, Kost-Alimova M, Protopopov A, Cadiñanos J, Horner JW, Maratos-Flier E, Depinho RA (2011) Telomerase reactivation reverses tissue degeneration in aged telomerase-deficient mice. Nature 469:102-106.

Jensen MB, González B, Castellano B, Zimmer J (1994) Microglial and astroglial reactions to anterograde axonal degeneration: a histochemical and immunocytochemical study of the adult rat fascia dentata after entorhinal perforant path lesions. Exp Brain Res 98:245-260.

John JA, Key B (2003) Axon mis-targeting in the olfactory bulb during regeneration of olfactory neuroepithelium. Chem Senses 28:773-779.

Kiyokage E, Pan YZ, Shao Z, Kobayashi K, Szabo G, Yanagawa Y, Obata K, Okano H, Toida K, Puche AC, Shipley MT (2010) Molecular identity of periglomerular and short axon cells. J Neurosci 30:1185-1196.

Kobayakawa K, Kobayakawa R, Matsumoto H, Oka Y, Imai T, Ikawa M, Okabe M, Ikeda T, Itohara S, Kikusui T, Mori K, Sakano H (2007) Innate versus learned odour processing in the mouse olfactory bulb. Nature 450:503-508.

Kosaka T, Kosaka K (2011) “Interneurons" in the olfactory bulb revisited. Neurosci Res 69:93-99.

Kreutzberg GW (1996) Microglia: a sensor for pathological events in the CNS. Trends Neurosci 19:312-318.

Lazarini F, Lledo PM (2011) Is adult neurogenesis essential for olfaction? Trends Neurosci 34:20-30.

Lazarini F, Mouthon MA, Gheusi G, de Chaumont F, Olivo-Marin JC, Lamarque S, Abrous DN, Boussin FD, Lledo PM (2009) Cellular and behavioral effects of cranial irradiation of the subventricular zone in adult mice. PLoS One 4:e7017.

Lledo PM, Gheusi G (2003) Olfactory processing in a changing brain. Neuroreport 14:1655-1663.

Lledo PM, Gheusi G, Vincent JD (2005) Information processing in the mammalian olfactory system. Physiol Rev 85:281-317.

Lledo PM, Alonso M, Grubb MS (2006) Adult neurogenesis and functional plasticity in neuronal circuits. Nat Rev Neurosci 7:179-193.

Mandairon N, Sacquet J, Jourdan F, Didier A (2006) Long-term fate and distribution of newborn cells in the adult mouse olfactory bulb: influences of olfactory deprivation. Neuroscience 141:443-451.
Marín-Teva JL, Dusart I, Colin C, Gervais A, van Rooijen N, Mallat M (2004) Microglia promote the death of developing Purkinje cells. Neuron 41:535-547.

Ming GL, Song H (2011) Adult neurogenesis in the mammalian brain: significant answers and significant questions. Neuron 70:687-702.

Monje ML, Toda H, Palmer TD (2003) Inflammatory blockade restores adult hippocampal neurogenesis. Science 302:1760-1765.

Nimmerjahn A, Kirchhoff F, Helmchen F (2005) Resting microglial cells are highly dynamic surveillants of brain parenchyma in vivo. Science 308:1314-1318.

Ono K, Takebayashi H, Ikenaka K (2009) Olig2 transcription factor in the developing and injured forebrain; cell lineage and glial development. Mol Cells 27:397-401.

Paolicelli RC, Bolasco G, Pagani F, Maggi L, Scianni M, Panzanelli P, Giustetto M, Ferreira TA, Guiducci E, Dumas L, Ragozzino D, Gross CT (2011) Synaptic pruning by microglia is necessary for normal brain development. Science 333:1456-1458.

Parrish-Aungst S, Kiyokage E, Szabo G, Yanagawa Y, Shipley MT, Puche AC (2011) Sensory experience selectively regulates transmitter synthesis enzymes in interglomerular circuits. Brain Res 1382:70-76.

Petreanu L, Alvarez-Buylla A (2002) Maturation and death of adult-born olfactory bulb granule neurons: role of olfaction. J Neurosci 22:6106-6113.

Pluchino S, Muzio L, Imitola J, Deleidi M, Alfaro-Cervello C, Salani G, Porcheri C, Brambilla E, Cavasinni F, Bergamaschi A, Garcia-Verdugo JM, Comi G, Khoury SJ, Martino G (2008) Persistent inflammation alters the function of the endogenous brain stem cell compartment. Brain 131:2564-2578.

Ponomarev ED, Shriver LP, Maresz K, Dittel BN (2005) Microglial cell activation and proliferation precedes the onset of CNS autoimmunity. J Neurosci Res 81:374-389.

Prinz M, Priller J, Sisodia SS, Ransohoff RM (2011) Heterogeneity of CNS myeloid cells and their roles in neurodegeneration. Nat Neurosci 13:1227-1235.

Ransohoff RM, Cardona AE (2010) The myeloid cells of the central nervous system parenchyma. Nature 468:253-262.

Sahay A, Scobie KN, Hill AS, O'Carroll CM, Kheirbek MA, Burghardt NS, Fenton AA, Dranovsky A, Hen R (2011) Increasing adult hippocampal neurogenesis is sufficient to improve pattern separation. Nature 472:466-470.

Sakamoto M, Imayoshi I, Ohtsuka T, Yamaguchi M, Mori K, Kageyama R (2011) Continuous neurogenesis in the adult forebrain is required for innate olfactory responses. Proc Natl Acad Sci U S A 108:8479-8484.

Sawada M, Kaneko N, Inada H, Wake H, Kato Y, Yanagawa Y, Kobayashi K, Nemoto T, Nabekura J, Sawamoto K (2011) Sensory input regulates spatial and subtype-specific patterns of neuronal turnover in the adult olfactory bulb. J Neurosci 31:11587-11596.

Schwob JE (2002) Neural regeneration and the peripheral olfactory system. Anat Rec 269:33-49.

Sierra A, Encinas JM, Deudero JJ, Chancey JH, Enikolopov G, OverstreetWadiche LS, Tsirka SE, Maletic-Savatic M (2010) Microglia shape adult hippocampal neurogenesis through apoptosis-coupled phagocytosis. Cell Stem Cell 7:483-495.

Snyder JS, Soumier A, Brewer M, Pickel J, Cameron HA (2011) Adult hippocampal neurogenesis buffers stress responses and depressive behaviour. Nature 476:458-461.

Strick-Marchand H, Masse GX, Weiss MC, Di Santo JP (2008) Lymphocytes support oval cell-dependent liver regeneration. J Immunol 181:2764-2771

Tepavčević V, Lazarini F, Alfaro-Cervello C, Kerninon C, Yoshikawa K, José Manuel Garcia-Verdugo JM, Lledo PM, Nait-Oumesmar B, Baron-Van Evercooren A (2011) Olfactory deficits following inflammationinduced subventricular zone dysfunction in a targeted mouse model of multiple sclerosis. J Clin Invest 121:4722-4734.

Tham TN, Lazarini F, Franceschini IA, Lachapelle F, Amara A, Dubois-Dalcq M (2001) Developmental pattern of expression of the alpha chemokine stromal cell-derived factor 1 in the rat central nervous system. Eur J Neurosci 13:845-856.

Tikka TM, Koistinaho JE (2001) Minocycline provides neuroprotection against $N$-methyl-D-aspartate neurotoxicity by inhibiting microglia. J Immunol 166:7527-7533.

Tikka T, Fiebich BL, Goldsteins G, Keinanen R, Koistinaho J (2001a) Minocycline, a tetracycline derivative, is neuroprotective against excitotoxicity by inhibiting activation and proliferation of microglia. J Neurosci 21:2580-2588. 
Tikka T, Usenius T, Tenhunen M, Keinänen R, Koistinaho J (2001b) Tetracycline derivatives and ceftriaxone, a cephalosporin antibiotic, protect neurons against apoptosis induced by ionizing radiation. J Neurochem 78:1409-1414.

Valley MT, Mullen TR, Schultz LC, Sagdullaev BT, Firestein S (2009) Ablation of mouse adult neurogenesis alters olfactory bulb structure and olfactory fear conditioning. Front Neurosci 3:51.

Vedin V, Slotnick B, Berghard A (2004) Zonal ablation of the olfactory sensory neuroepithelium of the mouse: effects on odorant detection. Eur J Neurosci 20:1858-1864.

Wu DC, Jackson-Lewis V, Vila M, Tieu K, Teismann P, Vadseth C, Choi DK, Ischiropoulos H, Przedborski S (2002) Blockade of microglial activation is neuroprotective in the 1-methyl-4-phenyl-1,2,3,6-tetrahydropyridine mouse model of Parkinson disease. J Neurosci 22:1763-1771.

Yamaguchi M, Mori K (2005) Critical period for sensory experiencedependent survival of newly generated granule cells in the adult mouse olfactory bulb. Proc Natl Acad Sci U S A 102:9697-9702.

Yokoyama TK, Mochimaru D, Murata K, Manabe H, Kobayakawa K, Kobay- akawa R, Sakano H, Mori K, Yamaguchi M (2011) Elimination of adultborn neurons in the olfactory bulb is promoted during the postprandial period. Neuron 71:883-897.

Yrjänheikki J, Keinänen R, Pellikka M, Hökfelt T, Koistinaho J (1998) Tetracyclines inhibit microglial activation and are neuroprotective in global brain ischemia. Proc Natl Acad Sci U S A 95:15769-15774.

Yrjänheikki J, Tikka T, Keinänen R, Goldsteins G, Chan PH, Koistinaho J (1999) A tetracycline derivative, minocycline, reduces inflammation and protects against focal cerebral ischemia with a wide therapeutic window. Proc Natl Acad Sci U S A 96:13496-13500.

Zattoni M, Mura ML, Deprez F, Schwendener RA, Engelhardt B, Frei K, Fritschy JM (2011) Brain infiltration of leukocytes contributes to the pathophysiology of temporal lobe epilepsy. J Neurosci 31: 4037-4050.

Ziv Y, Ron N, Butovsky O, Landa G, Sudai E, Greenberg N, Cohen H, Kipnis J, Schwartz M (2006) Immune cells contribute to the maintenance of neurogenesis and spatial learning abilities in adulthood. Nat Neurosci 9:268-275. 